\title{
Treatment of Hepatitis C in Patients Undergoing Immunosuppressive Drug Therapy
}

\author{
Kohtaro Ooka ${ }^{1}$ and Joseph K. Lim*2 \\ ${ }^{1}$ Department of Internal Medicine, Yale University School of Medicine, New Haven, CT, USA; ${ }^{2}$ Yale Liver Center, \\ Section of Digestive Diseases, Yale University School of Medicine, New Haven, CT, USA
}

\begin{abstract}
With 185 million people chronically infected globally, hepatitis C is a leading bloodborne infection. All-oral regimens of direct acting agents have superior efficacy compared to the historical interferon-based regimens and are significantly more tolerable. However, trials of both types of regimens have often excluded patients on immunosuppressive medications for reasons other than organ transplantation. Yet, these patients-most often suffering from malignancy or autoimmune diseases-could stand to benefit from these treatments. In this study, we systematically review the literature on the treatment of hepatitis $C$ in these neglected populations. Research on patients with organ transplants is more robust and this literature is reviewed here non-systematically. Our systematic review produced 2273 unique works, of which 56 met our inclusion criteria and were used in our review. The quality of data was low; only 3 of the 56 studies were randomized controlled trials. Sustained virologic response was reported sporadically. Interferon-containing regimens achieved this end-point at rates comparable to that in immunocompetent individuals. Severe adverse effects and death were rare. Data on all-oral regimens were sparse, but in the most robust study, rates of sustained virologic response were again comparable to immunocompetent individuals (40/41). Efficacy and safety of interferoncontaining regimens and all-oral regimens were similar to rates
\end{abstract}

Keywords: MeSH termsHepatitis C/dt [drug therapy]; Interferons; Direct acting antivirals; Immunosuppressive agents; Chemotherapy.

Abbreviations: 5FU, 5-fluorouracil; AASLD, American Association for the Study of Liver Diseases; $A B X$, antibiotics; $A E$, adverse effect; $A I H$, autoimmune hepatitis; ALL, acute lymphoblastic leukemia; APASL, Asian Pacific Association for the Study of Liver; ASA, aminosalicylic acid; AT, antiviral therapy; BFM, BerlinFrankfurt-Münster; CD, Crohn's disease; CR, complete response; CRP, C-reactive protein; DAA, direct acting antiviral; EASL, European Association for the Study of Liver; EPO, erythropoietin; ESRD, end-stage renal disease; EVR, early viral response; G-CSF, granulocyte-colony stimulating factor; Hb, hemoglobin; HBV, hepatitis B virus; HCC, hepatocellular carcinoma; HCV, hepatitis C virus; HIV human immunodeficiency virus; IBD, inflammatory bowel disease; IDSA, Infectious Diseases Society of America; IFN, interferon; IS, immunosuppression; MM, multiple myeloma; MPGN, membranoproliferative glomerulonephritis; MTX, methotrexate; NHL, non-Hodgkin's lymphoma; NK cell, natural killer cell; NR, no response; PASI, psoriasis area severity index; peg, polyethylene glycol; PLT, platelets; PR, partial response; QD, daily; RA, rheumatoid arthritis; RBV, ribavirin; RNA, ribonucleic acid; SSD, sickle cell disease; SVR, sustained virologic response; TNF- $\alpha$, tumor necrosis factor- $\alpha$; TRAIL, TNF-related apoptosis-inducing ligand UC, ulcerative colitis; VL, viral load; WBC, white blood cells; wnl, within normal limits; XELOX, Xeloda-oxaliplatin.

Received: 13 April 2016; Revised: 22 June 2016; Accepted: 12 July 2016

DOI: $10.14218 / \mathrm{JCTH} .2016 .00017$.

*Correspondence to: Joseph K. Lim, Yale Liver Center, Section of Digestive Diseases, Yale University School of Medicine, 333 Cedar Street, LMP 1080, New Haven, CT 06520-8019, USA. Tel: +1-203-737-6063, Fax: +1-203-7857273, E-mail: joseph.lim@yale.edu in immunocompetent individuals; however, there were few interventional trials. The large number of case reports and case series makes conclusions vulnerable to publication bias. While firm conclusions are challenging, given the dearth of high-quality studies, our results demonstrate that antiviral therapy can be safe and effective. The advent of all-oral regimens offers patients and clinicians greatly increased chances of cure and fewer side effects. Preliminary data reveal that these regimens may confer such benefits in immunosuppressed individuals as well. More prospective interventional trials would greatly benefit the many patients with chronic hepatitis $C$ on immunosuppressive therapies.

(C) 2016 The Second Affiliated Hospital of Chongqing Medical University. Published by XIA \& HE Publishing Inc. All rights reserved.

\section{Introduction}

\section{Background}

More than 185 million people are chronically infected with hepatitis $C$ virus (HCV) globally. ${ }^{1}$ In the United States and Canada, an estimated 4.4 million persons have chronic HCV infection. Chronic hepatitis $\mathrm{C}$ is associated with substantial morbidity and mortality due to progressive liver fibrosis, liver cirrhosis, liver cancer, liver failure and need for liver transplantation. Recent advances in antiviral therapy based on all-oral, interferon (IFN)-free regimens with direct acting antiviral agents (DAAs) have resulted in significant improvements in safety and viral eradication rates, also known as sustained virologic response (SVR). However, outside of the organ transplant context, very limited data are available that address safety and efficacy in patients undergoing immunosuppressive drug therapy. Although clinical trials have addressed specific populations that are immunocompromised, including those with human immunodeficiency virus (HIV) coinfection and post-liver or -kidney transplantation, patients undergoing other forms of immunosuppressive drug therapy in the context of cancer chemotherapy and the treatment of autoimmune conditions have generally been excluded. As such, the available literature addressing these populations has been limited primarily to case reports or series and to historical IFN-based regimens. Due to the high prevalence of autoimmune conditions and cancer in the general population $^{2}$ and among those with chronic hepatitis $C$, more evidence-based guidance is needed to inform clinicians of the implications of immunosuppressive drug therapy on HCV treatment. Herein, we report the results of a systematic 
review of available literature addressing HCV treatment in patients undergoing pharmacologic immunosuppression, focusing on immunosuppression for purposes other than organ rejection, and identify key gaps in the evidence that form the basis for future research priorities.

\section{Chronic Hepatitis C in Immunosuppressed Patients}

The immunopathogenesis of HCV infection is complex. Immunosuppression might be expected to reduce host-mediated inflammatory pathways that lead to liver damage; it may also reduce immune defenses against direct virally mediated liver injury. ${ }^{3}$ Steroids used in patients with hepatitis C/autoimmune hepatitis (AIH) overlap syndrome have led to clinical, biochemical and histologic improvements, despite an increase in viral load (VL). ${ }^{4-9}$ Inhibitors of tumor necrosis factor- $\alpha$ $(\mathrm{TNF}-\alpha)$ appear to be safe for use in patients with HCV. ${ }^{10-12}$ Recent studies have argued that rates of hepatocellular carcinoma ( $\mathrm{HCC}$ ) in patients with $\mathrm{HCV}$ who were treated for psoriasis with anti-TNF- $\alpha$ agents are no higher than in those not on TNF- $\alpha$ inhibitors, which raises the possibility of a therapeutic role for TNF- $\alpha$ inhibitors for psoriasis in patients with chronic HCV infection. ${ }^{13}$ Among patients with inflammatory bowel disease (IBD) and HCV infection who are on immunosuppressive therapy, the rate of progression of fibrosis is similar to rates reported in patients not on immunosuppressive therapy. ${ }^{14}$

\section{Scientific Rationale for Limiting Treatment}

Treatment of HCV in immunosuppressed patients during the IFN era was complicated by varying effects on HCV and the disease being treated with immunosuppressive agents. Immunosuppression can cause worsening of liver dysfunction in patients infected with $\mathrm{HCV}^{14}$ For patients on cytotoxic chemotherapy, this may lead to interruption or cessation of chemotherapy, as is reportedly the case for nearly $50 \%$ of patients. ${ }^{15}$ Secondly, IFN can induce flares of autoimmune disorders. ${ }^{16-18}$

There are mechanistic reasons to believe that IFN-based treatment will be less effective in immunosuppressed patients. IFN-based therapy reduces VL through immune-mediated and non-immune-mediated mechanisms. It promotes T-cell survival and proliferation, both of which are strongly associated with successful IFN therapy. ${ }^{19,20}$ This is in line with primate studies that have shown that viral clearance of initial $\mathrm{HCV}$ infection is dependent on cytotoxic T-cells. ${ }^{21-23}$ IFN also up-regulates natural killer cell production of the apoptotic particle, TNF-related apoptosis-inducing ligand (TRAIL). ${ }^{24,25}$ Ribavirin (RBV) possesses T-cell-mediated antiviral effects. ${ }^{20,26}$ Immunosuppressive therapy, especially cytotoxic chemotherapy, would inhibit innate and adaptive immunity and could be expected to mitigate the immune-mediated effects of IFN and RBV.

However, the success of DAAs in achieving SVR without IFN demonstrates that inhibiting viral replication without inducing an additional immune response may be sufficient to clear HCV. This may be explained partly by the fact that there are no reservoirs of latent virus in infected individuals. ${ }^{25}$ It is not clear, however, to what extent an intact immune system is necessary for viral eradication with DAAs.

Immunosuppression is a critical component of posttransplant maintenance therapy where concerns of rejection are in opposition to concerns of HCV reactivation. ${ }^{27}$ Theoretically, immunosuppression reduces the former while increas- ing the chance of the latter recurring, although the risk is lower than for hepatitis B virus (HBV) reactivation. ${ }^{28,29}$ In addition, withdrawal of immunosuppressive agents can cause a surge in immune response, leading to flares of hepatitis. ${ }^{28,30}$ Experience with transplant patients, however, shows that HCV can be treated safely and effectively in the setting of immunosuppression. With IFN-free regimens, rates of SVR in transplant patients without cirrhosis are similar to those in pre-transplant patients. ${ }^{31-34}$

IFN-based treatment is only moderately effective and has frequent and significant side effects and many contraindications. ${ }^{35,36}$ Significant adverse effects of combination IFN and RBV include depression, cytopenias and flu-like symptoms. Importantly, it is contraindicated in the presence of conditions known to be exacerbated by IFN, such as autoimmune hemolytic anemia, ${ }^{37}$ thyroid disease ${ }^{38}$ and $\mathrm{AIH} .{ }^{39}$ Approximately one-quarter of patients who begin the IFN/RBV regimen do not complete the full treatment course. ${ }^{40}$

DAAs are more efficacious, safer and more tolerable $e^{41-43}$ and do not cause potent immune stimulation. Patients who would not qualify for IFN-containing regimens-those with contraindications or severe comorbidities and those for whom the lower cure rate of IFN-containing regimens would be insufficient to justify the risk and cost-might benefit from DAAs. This raises the possibility that patients on immunosuppression may undergo treatment for HCV with IFN-free regimens and expect high rates of viral eradication and few serious adverse effects.

However, understanding of the effects of DAAs in patients on immunosuppression is limited by the fact that randomized controlled trials of DAAs have excluded such patients based on presence of malignancy, cytopenias (e.g. anemia, neutropenia, thrombocytopenia) and contraindications to IFN (e.g. chronic autoimmune diseases). ${ }^{44-47}$

\section{Transplant Experience}

\section{Liver Transplant}

The literature supporting the treatment of hepatitis $C$ in liver transplant recipients is more robust than that for patients on immunosuppressive drug therapy for other indications. In patients with HCV prior to liver transplant, recurrence is nearly universal. Historical IFN-based regimens used in patients with recurrent post-transplant HCV were poorly tolerated and associated with low rates of SVR. A systematic review of IFN-based treatment in liver transplant recipients on immunosuppressive regimens (mostly comprised of tacrolimus, cyclosporine and corticosteroids) revealed pooled SVR rates (24\% and $27 \%$ with IFN/RBV and polyethylene glycol (peg)IFN/RBV, respectively). ${ }^{48}$ Acute rejection occurred in $2 \%$ to $5 \%$ of patients, and a least two-thirds required dose reduction or early discontinuation. More recent reports cite SVR rates that are lower than $50 \%{ }^{49-52}$ and acute rejection rates that are not significantly higher than those achieved with placebo. 49,53

Updated consensus guidelines of the American Association for the Study of Liver Diseases (AASLD) and Infectious Diseases Society of America (IDSA) now recommend alloral treatment of hepatitis $C$ in liver transplant recipients. ${ }^{54}$ Randomized controlled trials have found SVR rates of over $90 \%$ in post-transplant patients with F0-F3 fibrosis and compensated cirrhosis, and of $80-85 \%$ in post-transplant patients with Child $\mathrm{B}$ or $\mathrm{C}$ decompensated cirrhosis undergoing 
antiviral therapy with sofosbuvir/ledipasvir or sofosbuvir/ daclatasvir. ${ }^{44,55,56}$ Serious adverse effects attributed to antiviral therapy were rare, and both regimens were well tolerated. Drug-drug interactions between DAAs and immunosuppressive drugs such as tacrolimus and cyclosporine are common, and require careful attention prior to and throughout the treatment course.

\section{Kidney Transplant}

No drugs are currently approved for the treatment of hepatitis C in kidney transplant recipients. IFN-containing regimens are generally avoided in renal transplant recipients because of an increased risk of graft rejection. A 2014 meta-analysis showed that IFN-containing regimens achieved SVR in 34\%, but approximately one-third of patients failed to complete the treatment course, of whom approximately half discontinued due to graft dysfunction. ${ }^{57}$ Accordingly, renal society guidelines from the IFN era suggest treating hepatitis $C$ in renal transplant recipients only when the benefits outweigh the significant risk of rejection from IFN (e.g. fibrosing cholestatic hepatitis, cirrhosis or life-threatening vasculitis). ${ }^{58}$ These guidelines suggested that although conventional immunosuppression can be used in this context, the evidence base to support specific therapies post-renal transplant is largely of very low quality, including case reports and case series.

Recent reports do suggest that all-oral DAA regimens appear to be well tolerated and efficacious in patients following renal transplantation..$^{59-62}$ One randomized controlled trial by Colombo et $\mathrm{al}^{63}$ reported at the International Liver Congress in April 2016 revealed that sofosbuvir/ledipasvir for 12 or 24 weeks was associated with an SVR of $98 \%(112 / 114)$ in GT1 or 4 treatment-naïve or experienced patients post-renal transplant, and was associated with favorable safety, with no events of acute rejection.

\section{Other Transplant}

We are aware of no studies examining the treatment of hepatitis $C$ in recipients of other types of solid organ transplants. We were also unable to find studies in patients who had received stem cell transplants. One series of hepatitis $C$ treatment in patients who had received bone marrow transplants excluded patients on immunosuppressive drug therapy. ${ }^{64}$ A letter to the editor reports outcomes of five patients treated for hepatitis $C$ after autologous stem cell transplantation but does not report immunosuppressive regimens that were used. ${ }^{65}$

\section{Methods}

We conducted a systematic search of Medline (OVID), Cochrane Library, Embase and CINAHL in February 2016 for publications with the following terms: antineoplastic protocols, chemotherapy, antineoplastic agents, neoplasms/drug therapy, immunosuppressive agents, glucocorticoids, TNF- $\alpha$, calcineurin inhibitors, and hepatitis c/drug therapy. We excluded citations with the keyword "organ transplantation" and limited our search to English language articles. Conference abstracts from the AASLD, the European Association for the Study of Liver (EASL), and the Asian Pacific Association for the Study of Liver (APASL) from 2015 and 2016 were reviewed in a targeted fashion, and one abstract from an international conference in February 2016 was included. ${ }^{66}$
Long-term steroid regimens with more than $20 \mathrm{mg}$ of prednisone equivalent per day were considered to be immunosuppressive. Patients who received rituximab administrations as early as 1 month before initiation of antiviral therapy were included. Otherwise, administration of any immunosuppressive agent while the patient was being treated for HCV was considered to be concomitant with antiviral therapy. Trials without clear description of the timing of drug therapy were excluded. Pharmacologic dosing trials were excluded as well.

Studies were characterized by their study design (e.g. randomized controlled trial), sample size, treatment regimens and outcomes. Outcomes for the disease for which immunosuppressive therapy was administered was judged to be positive if partial response or complete response was achieved or if otherwise described as being generally positive. If the treatment was repeated due to relapse, we chose to report the results of the first course only.

SVR was defined as undetectable HCV RNA at 12 weeks after the end of treatment for all-oral, IFN-free regimens, and 24 weeks after the end of treatment for historical IFN-based regimens. If RNA levels were not reported at 24 weeks but were reported at a later time point (e.g. at 36 weeks after the end of treatment) SVR at that point was used. Reports on cryoglobulinemic vasculitis are reported separately (i.e. not grouped by agent), as multiple classes of immunosuppressive therapies were often used and the primary intent of IFNbased treatment was as much treatment of vasculitis as treatment of HCV infection per se.

\section{Results}

\section{Literature Search Results}

A total of 2916 citations were retrieved through our search of the databases (Fig. 1). Of these, 143 were duplicates, leaving 2273 unique works. Abstracts from four international society meetings (AASLD, EASL, APASL, and Digestive Disease Week) were also reviewed to identify relevant studies, contributing one abstract from February $2016 .{ }^{66}$ The studies were screened by $\mathrm{KO}$ and 96 studies were identified as possibly meeting criteria. After further review, 56 were included in this systematic review (Fig. 1). The studies selected for this review included 8 prospective interventional studies ( $n=185$ patients), including 3 randomized controlled, trials ( $n=76$ patients), one non-randomized controlled trial $(n=76$ patients), and four other prospective interventional trials ( $n=33$ patients). The studies also included 4 prospective cohort studies ( $n=84$ patients), 15 retrospective cohort studies, case-control studies, and case series ( $n=80$ patients), and 29 case reports ( $n=33$ patients). Approximately $40 \%$ of studies addressed cryoglobulinemia (Table 2). Ten studies comprising only 19 patients reported the results of cancer patients. Five studies with an average of 31 patients each reported the results of immunosuppressive agents used for the treatment of hepatitis C. IBD and other autoimmune disorders (e.g. rheumatoid arthritis) made up the remainder (19 studies and 93 patients).

\section{Cryoglobulinemia and Vasculitis}

In HCV-associated cryoglobulinemic vasculitis, B-cell expansion causes elevated levels of immunoglobulins that in turn can lead to skin ulcers, renal disease, neuropathy and other 
Ooka K. et al: Hepatitis C treatment in immunosuppression

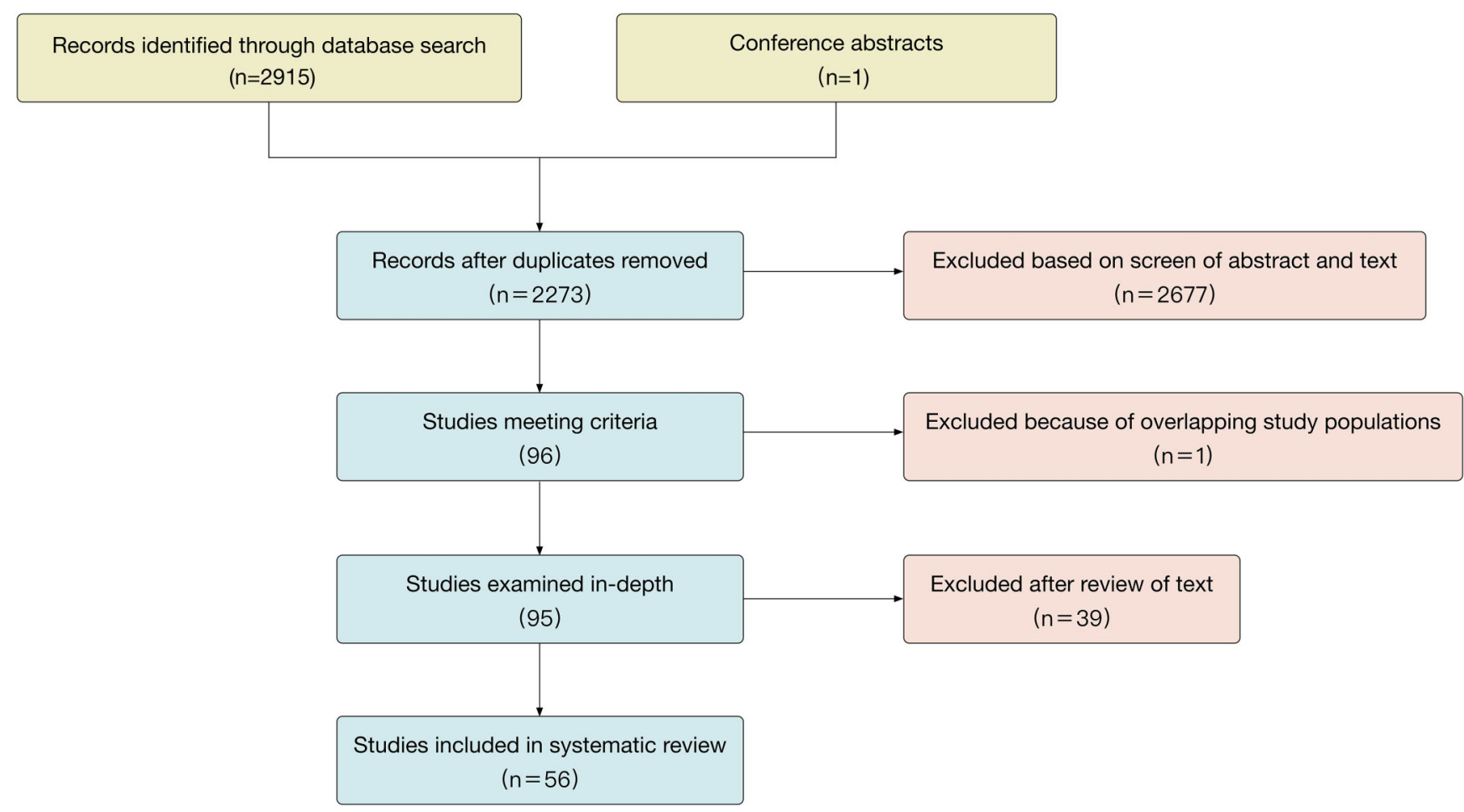

Fig. 1. PRISMA chart.

symptoms. ${ }^{67}$ Both IFN-based antiviral therapy and immunosuppressive agents (e.g. rituximab) are components of regimens used to treat HCV-associated vasculitis. ${ }^{68-70}$ A number of studies have investigated the use of combination antiviral therapy and anti-CD20 antibodies to treat HCV-associated cryoglobulinemia, vasculitis or a combination of the two. As the primary intent is resolution of symptoms and organ dysfunction, rather than treatment of $\mathrm{HCV}$, clinical response of renal function, skin ulcers and other manifestations of vasculitis are often described in detail but viral response rates, including SVR, are often not reported. Nonetheless, we can assess the efficacy and safety of anti-HCV agents used concomitantly with immunosuppressants in these settings.

In total, 22 studies reported outcomes of 116 patients (Table 3). In the nine studies that reported VL at 24 weeks after treatment or later, on aggregate, $56 \%$ of patients achieved

Table 1. Study designs

\begin{tabular}{lll}
\hline Study Design & Studies & Patients \\
\hline Case report & 29 & 33 \\
Case series & 10 & 44 \\
Case-control & 2 & 11 \\
Retrospective cohort & 3 & 25 \\
Prospective cohort & 4 & 84 \\
Prospective interventional & 4 & 33 \\
Non-randomized controlled trial & 1 & 76 \\
Randomized controlled trial & 3 & 76 \\
Total & $\mathbf{5 6}$ & $\mathbf{3 8 2}$ \\
\hline
\end{tabular}

SVR; this finding was roughly similar to the usual efficacy of the various IFN-based regimens used in these studies. Nine patients required cessation or interruption of therapy secondary to adverse effects related to the medications. In the three studies with more than 10 patients, 46 of 80 patients (58\%; range, 55-59\%) reached SVR; all three used rituximab with pegIFN and RBV. ${ }^{71-73}$ Similarly, clinical response of the cryoglobulinemia was seen in 84 of the 110 patients (76\%). Adverse effects of IFN, RBV and rituximab did not appear to be more common than in patients not on immunosuppressive therapy. In a prospective cohort study of 38 patients on rituximab and various corticosteroids, other immunosuppressive agents or plasma exchange, three patients died (cirrhosis, liver carcinoma, unknown) but mortality was not significantly different from the control group (2/55 died from liver carcinoma) ${ }^{71}$

Few studies report the use of DAAs in cryoglobulinemia or vasculitis. Humphries et $\mathrm{al}^{74}$ reported a case of cryoglobulinemic vasculitis manifesting as membranoproliferative glomerulonephritis (MPGN) and skin ulcers that was treated

Table 2. Reasons for immunosuppression

\begin{tabular}{lll}
\hline Reason for Immunosuppression & Studies & Patients \\
\hline Cryoglobulinemia/vasculitis & 22 & 116 \\
Cancer & 10 & 19 \\
HCV - trial & 5 & 154 \\
IBD & 8 & 60 \\
Autoimmune - Other & 11 & 33 \\
Total & $\mathbf{5 6}$ & $\mathbf{3 8 2}$ \\
\hline
\end{tabular}




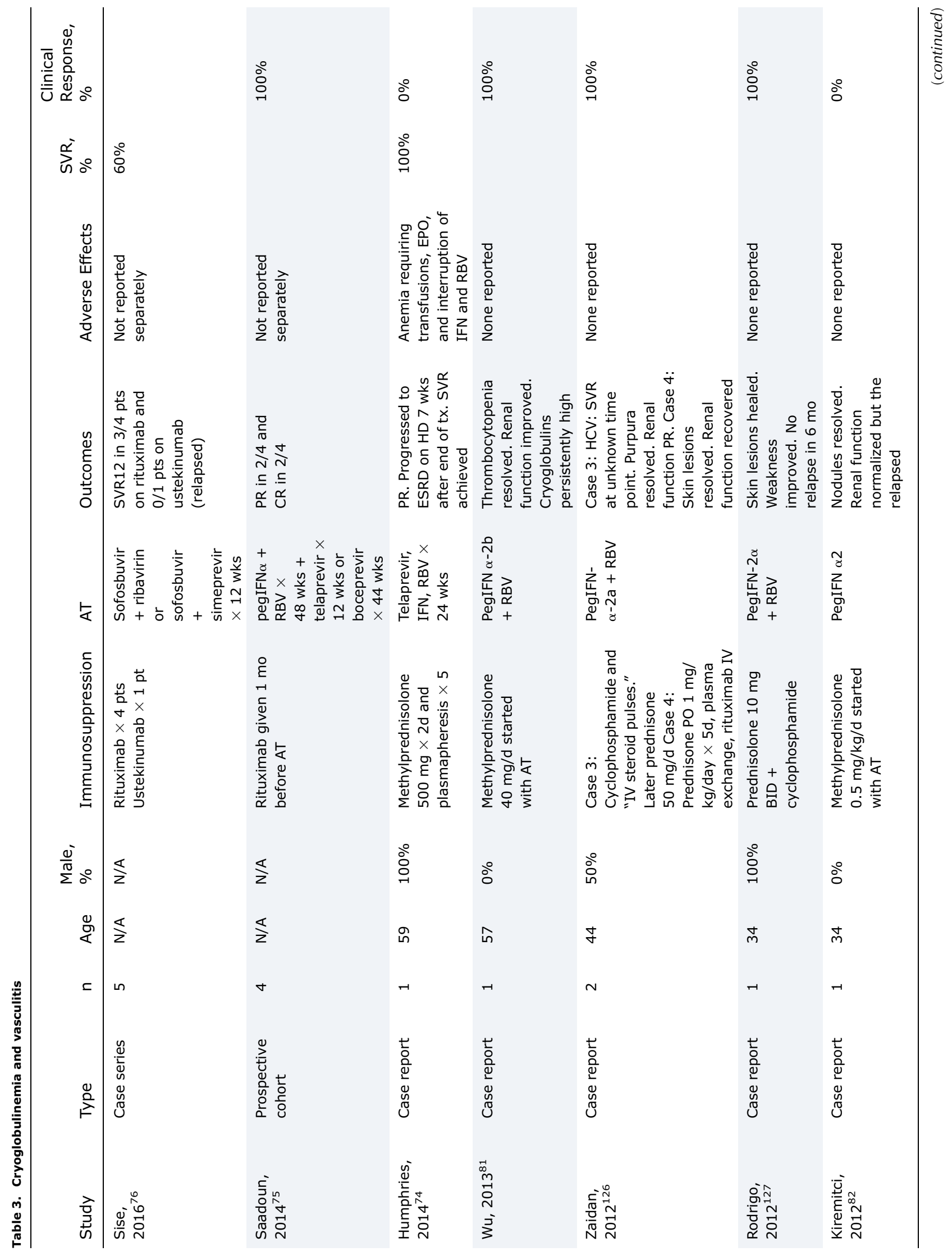




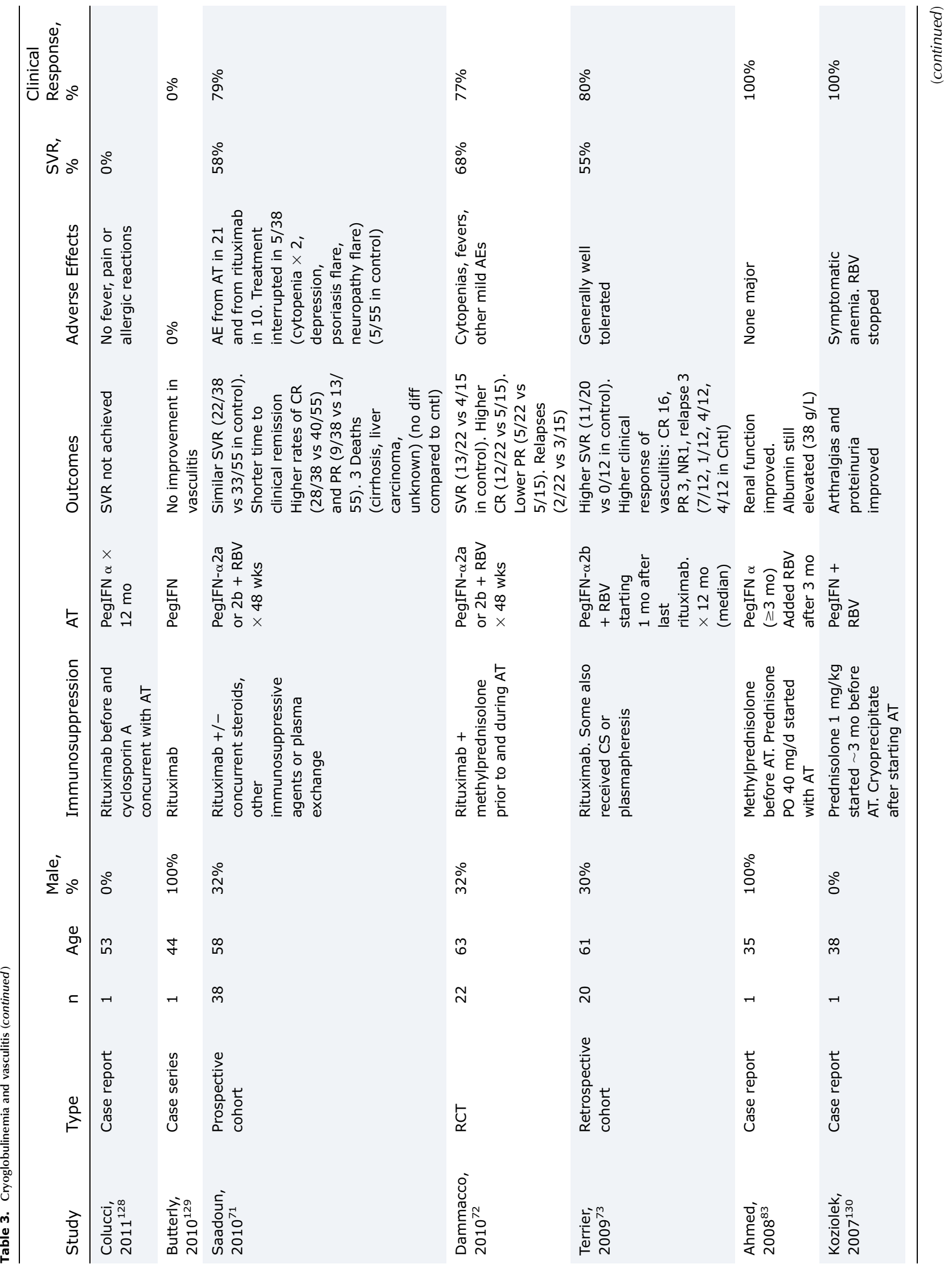




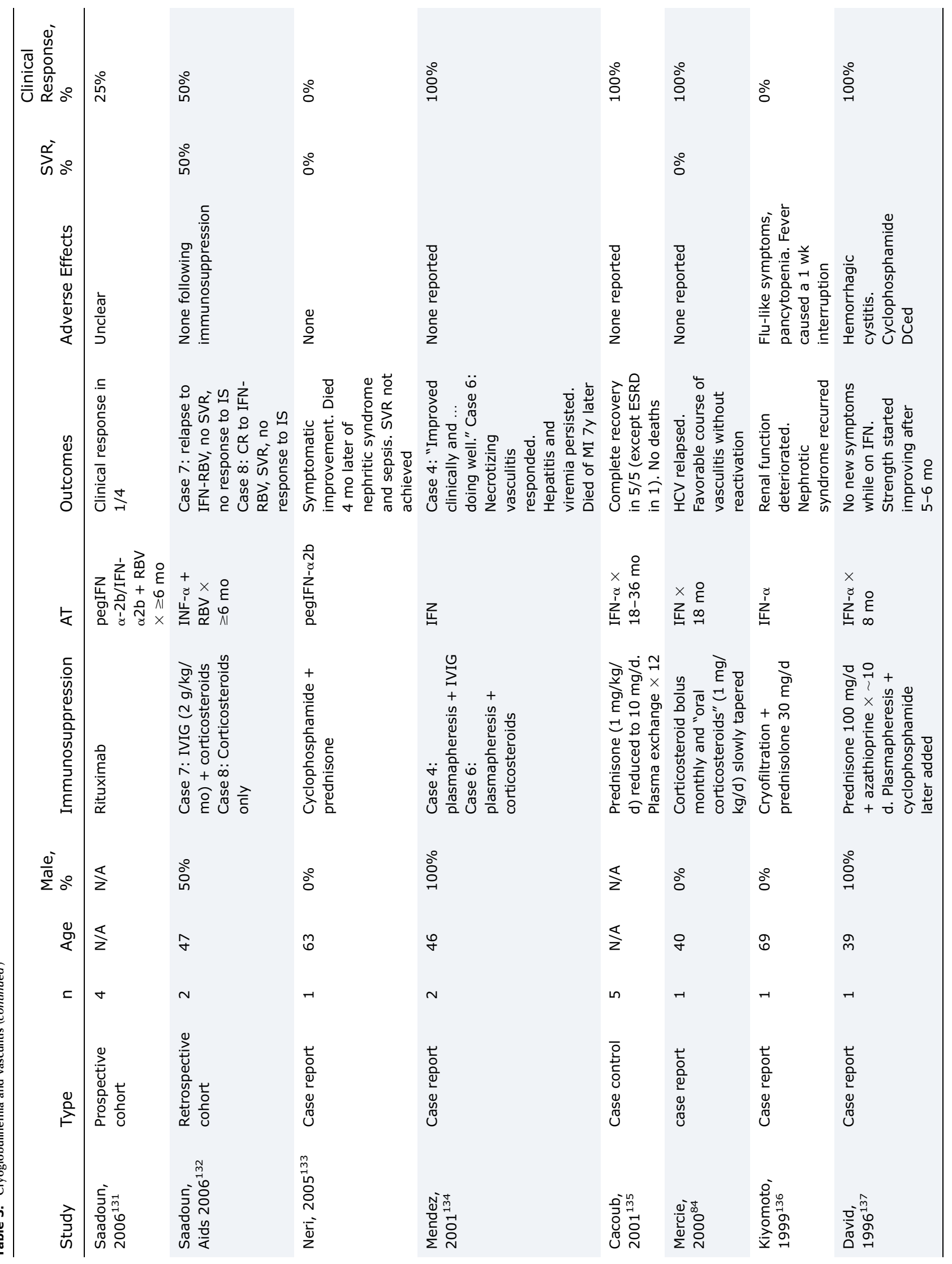


with telaprevir, pegIFN and RBV concurrent with methylprednisolone and plasmapheresis. SVR was achieved, but the MPGN progressed to end-stage renal disease by 7 weeks after treatment. The case was also complicated by anemia requiring interruption of treatment and transfusions of packed red blood cells. In a prospective cohort study of telaprevir or boceprevir and pegIFN and RBV in four patients who had been treated for mixed cryoglobulinemic vasculitis with rituximab 1 month prior, two patients achieved partial response and two achieved complete response; ${ }^{75}$ SVR was not reported.

In the only study addressing the use of an all-oral regimen, three out of four patients on rituximab treated with sofosbuvir with RBV or simeprevir achieved SVR12. ${ }^{76}$ One patient on ustekinumab (a monoclonal antibody that targets IL-12 and IL-23) experienced a relapse of HCV.

Overall, IFN-based antiviral therapy appears to perform reasonably well in patients on immunosuppressive therapy for cryoglobulinemia/vasculitis. The major caveats to these conclusions are that the quality of evidence is low, represented mostly by case reports and retrospective observational studies. DAAs were shown to be able to achieve SVR in this population, but with only three studies addressing this subject-of which two used regimens containing both DAAs and IFN-it is impossible to know if similar results can be expected in clinical practice.

\section{Glucocorticoids}

Glucocorticoids have potent anti-inflammatory and immunosuppressive effects at higher doses. They inhibit leukocyte infiltration into sites of tissue damage and repress transcription of inflammatory cytokines. ${ }^{77}$ Withdrawal of steroids can cause these inflammatory processes to rebound. Some have investigated the use of this phenomenon for the treatment of $\mathrm{HCV}$ infection with mixed effects. ${ }^{78-80}$

The effect of steroids can be clouded by other immunosuppressive agents that are frequently administered concomitantly. Five case reports discuss high-dose steroids used in the absence of other immunosuppressive therapies and concomitantly with antiviral therapy (Table 4). ${ }^{81-85}$ Four studies reported on patients with MPGN and/or vasculitis; three of four patients achieved a favorable clinical response and one of two achieved SVR. ${ }^{81-84}$ Overall, SVR was achieved in three of four patients for which it was reported. No major adverse effects were reported.

Efe et $\mathrm{al}^{86}$ reports the results of a retrospective study of patients with HCV infection and $\mathrm{AIH}$. Thirteen patients received immunosuppression with prednisone at a dose of 20-40 mg/day. An unknown number of these patients received azathioprine as well. After 3-6 months of immunosuppression, levels of alanine transaminase and aspartate transaminase fell below twice the upper limit of normal, and antiviral therapy with IFN with or without RBV was initiated. SVR was achieved in $7 / 13$ and no relapse of AIH was observed. A report of two patients with AIH and HCV treated with pegIFN- $\alpha 2 \mathrm{~b}$ and RBV while taking $20 \mathrm{mg} /$ day of prednisolone reported achievement of SVR and good clinical response for both. ${ }^{85}$ Overall, the use of glucocorticoids with IFN-based regimens achieved SVR in 10 of 17 patients (59\%).

Based on these reports, treatment of chronic HCV infection with IFN-based regimens in patients on immunosuppressive doses of corticosteroids appears as safe and as effective as in patients not on immunosuppression. This conclusion should be considered in light of the caveat that the data is sparse and of low quality. A single case series accounts for 13 of 19 total patients in these studies. Furthermore, these conclusions have become less relevant with the advent of DAAs. Unfortunately, there are no reports of all-oral DAA regimens used in patients on glucocorticoids in the absence of other immunosuppressive agents.

\section{Cytotoxic Chemotherapy for Cancer}

Treatment of chronic HCV infection in patients on chemotherapy for cancer presents a unique challenge and opportunity. Cirrhosis and chronic hepatitis are reportedly three-fold more common in those with cancer than in the general population. ${ }^{87}$ Studies in patients with hematological malignancies suggest the prevalence of chronic HCV infection may range between $1.5 \%$ and $32 \%$, depending on the type of malignancy and the population studied. ${ }^{88}$ Chronic infection with HCV is associated with 1.6-fold [lung cancer, non-Hodgkin's lymphoma (NHL)] to 48.6-fold (liver cancer) increased risk of cancer. ${ }^{89}$ AASLD guidelines do not address treatment of $\mathrm{HCV}$ in patients with cancer other than to recommend against monitoring for HCV recurrence in patients who achieved SVR. ${ }^{54}$ Large trials of antiviral therapy for HCV have excluded patients on chemotherapy, making the literature on this topic sparse.

Seven studies with a total of 11 patients describe IFNbased regimens administered concomitantly with cytotoxic chemotherapy for patients with cancer (Table 5). All but one is a case report. Six patients had solid tumors (colon, breast, $\mathrm{HCC}$ ) and five suffered from hematologic malignancies [acute lymphoblastic leukemia (ALL), NHL, multiple myeloma (MM)]. In the largest study, 5-fluorouracil (5FU) was infused into the hepatic artery in four patients with HCC. ${ }^{90}$ Partial response of the HCC was seen in all patients. SVR was not reported. Overall, three of five (60\%) patients in whom SVR was reported achieved this end-point. In two studies, HCV VL was undetectable at an unknown time point and SVR was not explicitly reported. ${ }^{90,91}$ One study reported achieving early virologic response but antiviral therapy was ongoing. ${ }^{92}$

Taken in aggregate, the studies reported positive clinical responses in 10 of 11 patients. In six patients with hematological malignancies, four (ALL in three, B-cell NHL in one) experienced remission. In a case report of MM, disease progressed to involve new compression fractures at 4 months after thalidomide was initiated.

Adverse events were generally mild and limited to those known to be associated with the agents used. Cytopenias were common in patients with hematological malignancies. In three studies (three patients total), therapy was interrupted or modified as a result. In one study of docetaxel and trastuzumab for breast cancer, grade 4 neutropenia and grade 3 hepatotoxicity caused a delay in antiviral therapy and chemotherapy. ${ }^{92}$

While these reports give us some sense of possible outcomes, it is undoubtedly too little to give clinicians much confidence when contemplating the treatment of HCV in their patients on cytotoxic chemotherapy. The paucity of data on this topic is especially unfortunate given that cancer is a relatively prevalent disease and that cytotoxic chemotherapy has long been a mainstay of therapy. Significantly, no studies report the use of modern all-oral DAA regimens in patients on cytotoxic chemotherapy for cancer. 
Ooka K. et al: Hepatitis C treatment in immunosuppression

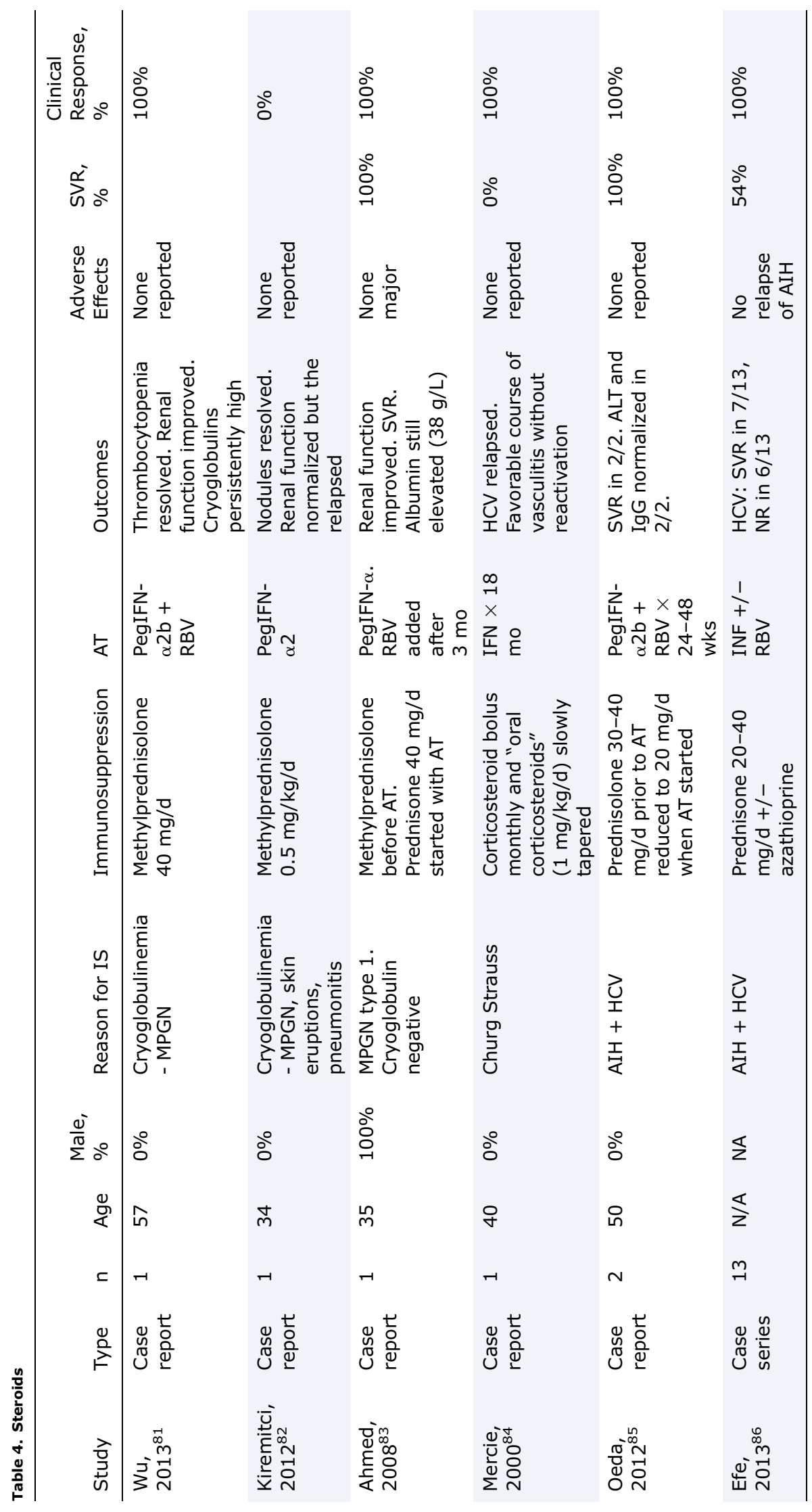




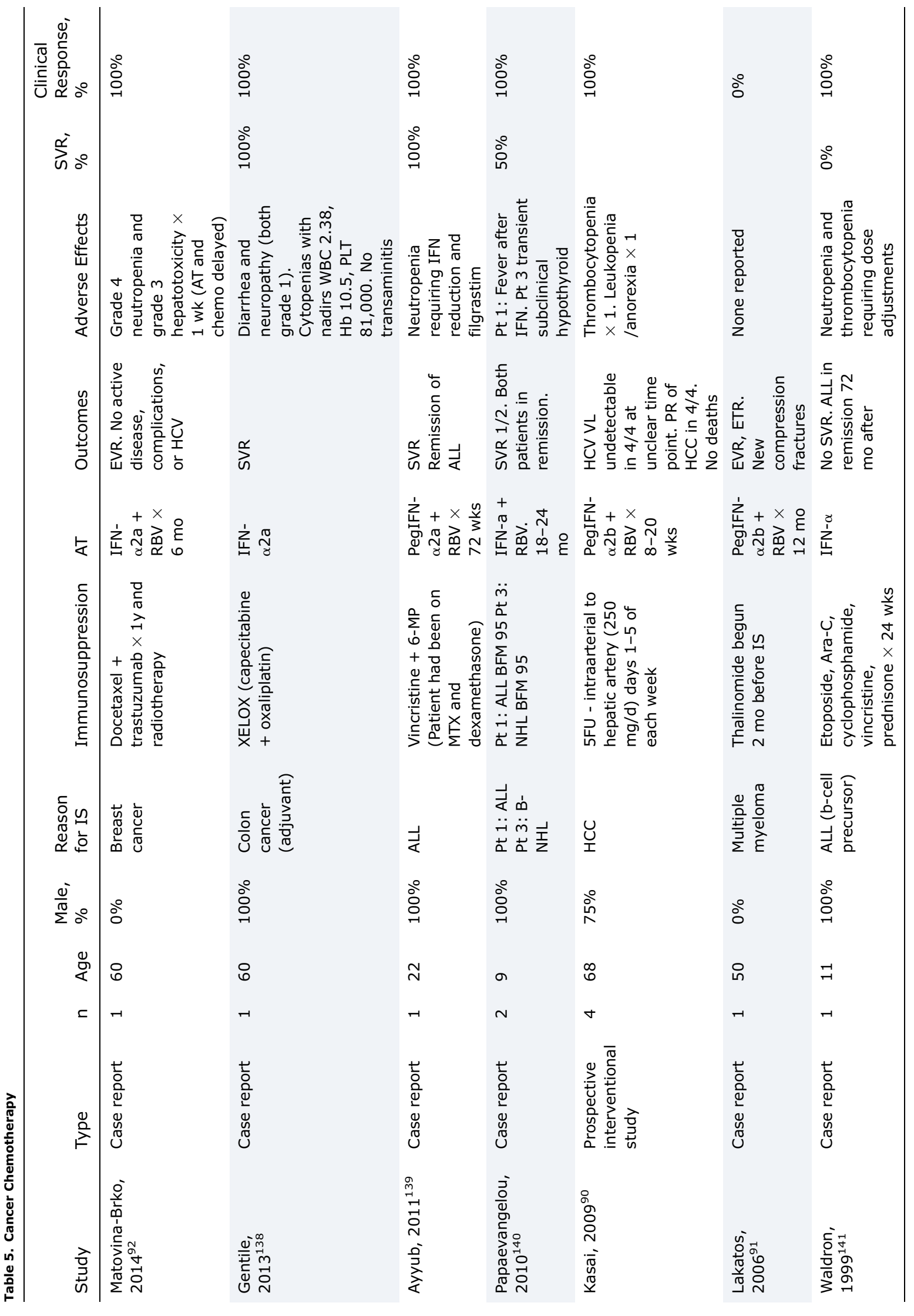




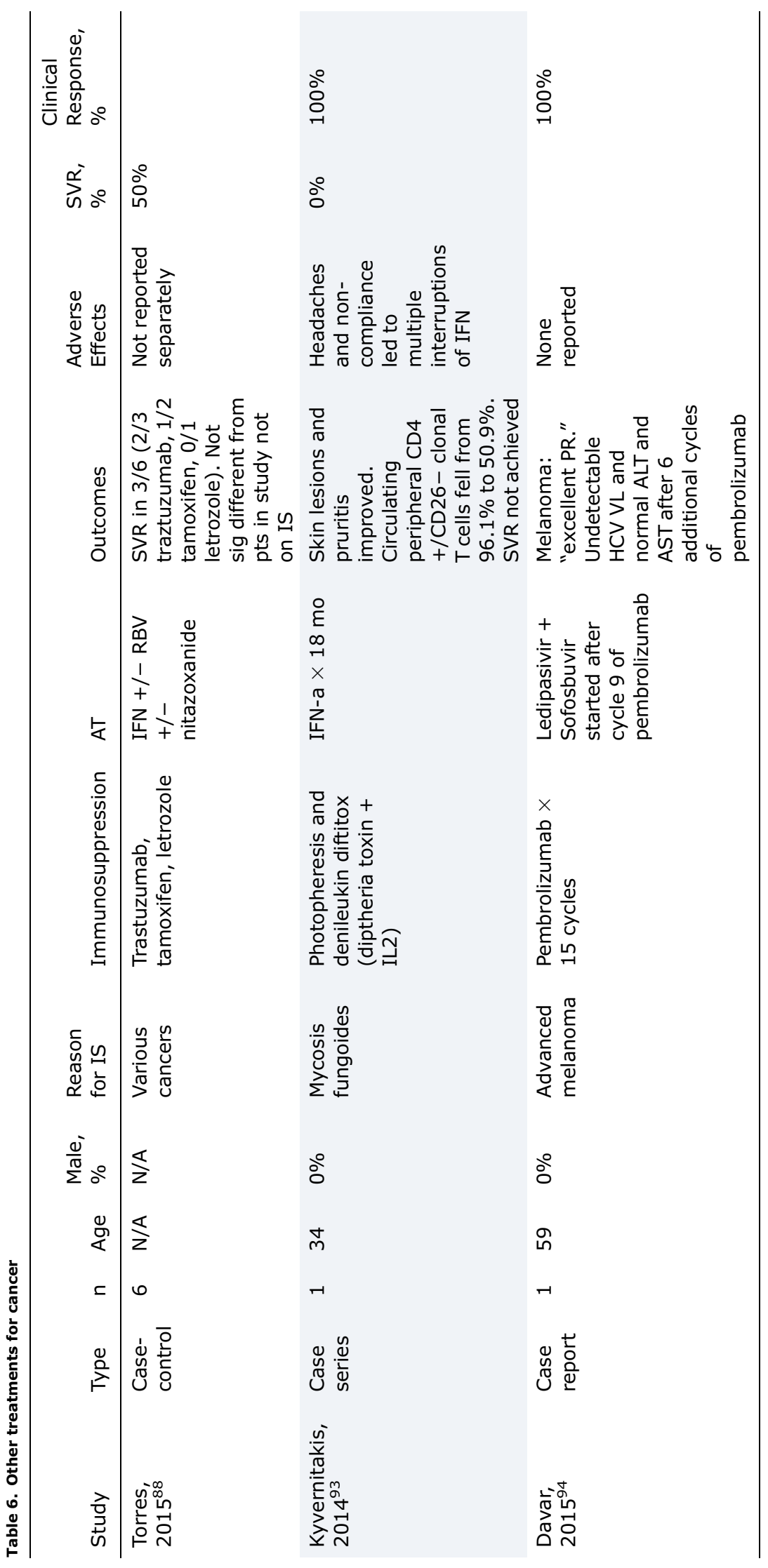




\section{Other Immunosuppressive Agents in Cancer}

In a study examining IFN-based antiviral therapy in the setting of various hormonal agents (trastuzumab, tamoxifen, letrozole), SVR was achieved in 3 of 6 patients (Table 6 ). ${ }^{88}$ Kyvernitakis et $\mathrm{al}^{93}$ describe the use of IFN in a patient on treatment with photopheresis and denileukin diftitox for mycosis fungoides; skin lesions improved in this study, but SVR was not achieved. One case report describes all-oral antiviral regimens in patients undergoing immunotherapy for cancer. ${ }^{94}$ Pembrolizumab combined with ledipasvir and sofosbuvir in a patient with advanced melanoma led to "excellent" response, normal transaminases and undetectable $\mathrm{VL}$ at an unknown time point. It should be noted that although antiviral therapy was started, at 9 cycles into a 15-cycle course of pembrolizumab it was not completely clear if pembrolizumab was continued while the patient was treated for HCV infection. However, given the novelty of the case-immunotherapy given concomitantly with DAAs-we felt somewhat compelled to include it.

\section{Trials of Immunosuppressive Agents for the Treatment of HCV Infection}

Three interventional studies comprising 97 patients examined the use of thalidomide and cyclosporin $A$ for the treatment of HCV infection (Table 7). SVR was achieved in 42/76 (55\%) patients in the largest study, a non-randomized controlled trial of cyclosporin A and IFN- $\alpha 2 b$ compared to IFN- $\alpha 2 b$ alone. ${ }^{95}$ There was no significant difference in discontinuation of therapy or adverse events. Two single-armed prospective interventional trials of chemotherapeutic agents and IFN for the treatment of HCV infection were unable to achieve SVR. In a trial of cyclosporin and IFN- $\alpha$ con- 1 , hypertension and neutropenia required dose reductions of cyclosporin and IFN respectively. ${ }^{96}$ In a trial of thalidomide and pegIFN- $\alpha 2 b$ with RBV, thalidomide was discontinued in 2 of 11 patients due to vasovagal syncope and delirium. ${ }^{97}$ Overall, it appears that the addition of cytotoxic chemotherapy reduces the efficacy of IFN-based antiviral therapy.

\section{TNF- $\alpha$ Inhibitors}

TNF- $\alpha$ is an inflammatory cytokine involved in the expression of other pro-inflammatory cytokines. Inhibitors of TNF- $\alpha$ are routinely used for the treatment of autoimmune disorders, such as IBD, rheumatoid arthritis and psoriasis. These agents, however, have been associated with an increased risk of serious infectious diseases, but data regarding worsening of $\mathrm{HCV}$ infection are conflicting. ${ }^{98-101}$ In a review of 216 patients (260 patient-years of follow-up) with HCV infection treated with TNF- $\alpha$ inhibitors, these agents were withdrawn due to suspected worsening HCV infection only three times. ${ }^{98}$

Five reports on TNF- $\alpha$ inhibitors describe etanercept being used with IFN-based treatments in a total of 25 patients (Table 8). ${ }^{13,102-105}$ Flares of underlying autoimmune disorders were rare-one patient had a flare of rheumatoid arthritis and one patient experienced a recurrence of neuralgia. A trial of etanercept in combination with IFN and RBV for the treatment of HCV achieved SVR in 8 of 19 patients (42\%), which was somewhat higher than in the control group $(8 / 25,32 \%)$ who were treated with IFN and RBV only. ${ }^{105}$ Two of 19 patients withdrew because of adverse effects, although nausea was less common than in a control group. Otherwise, SVR was

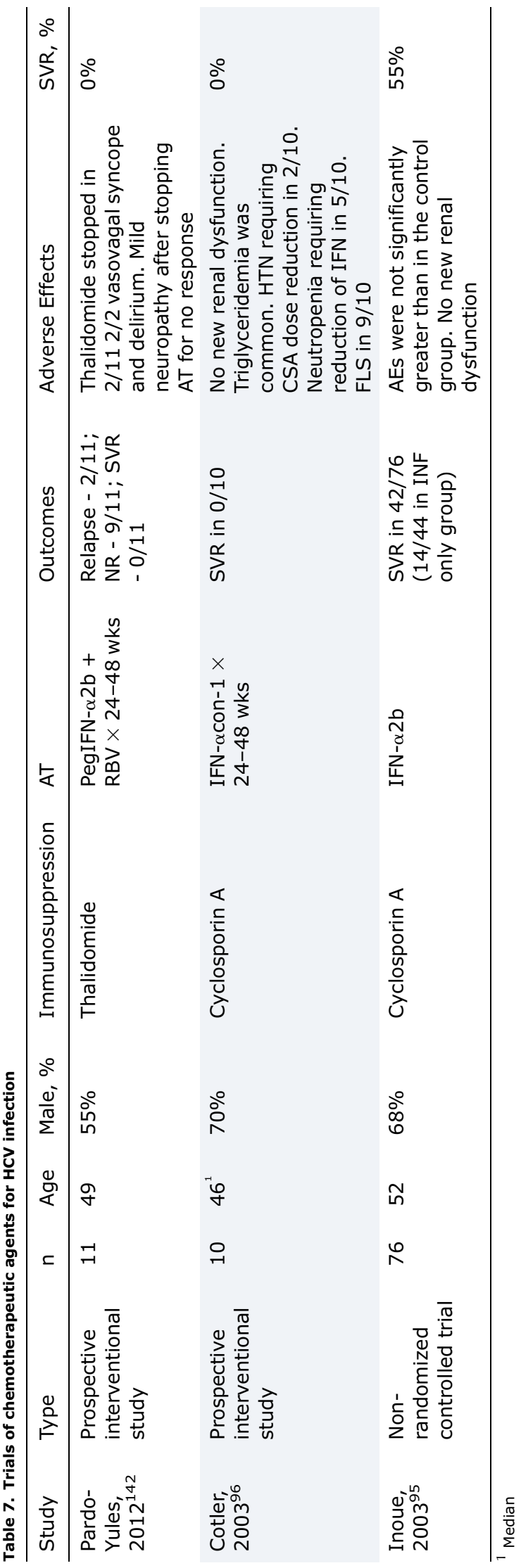




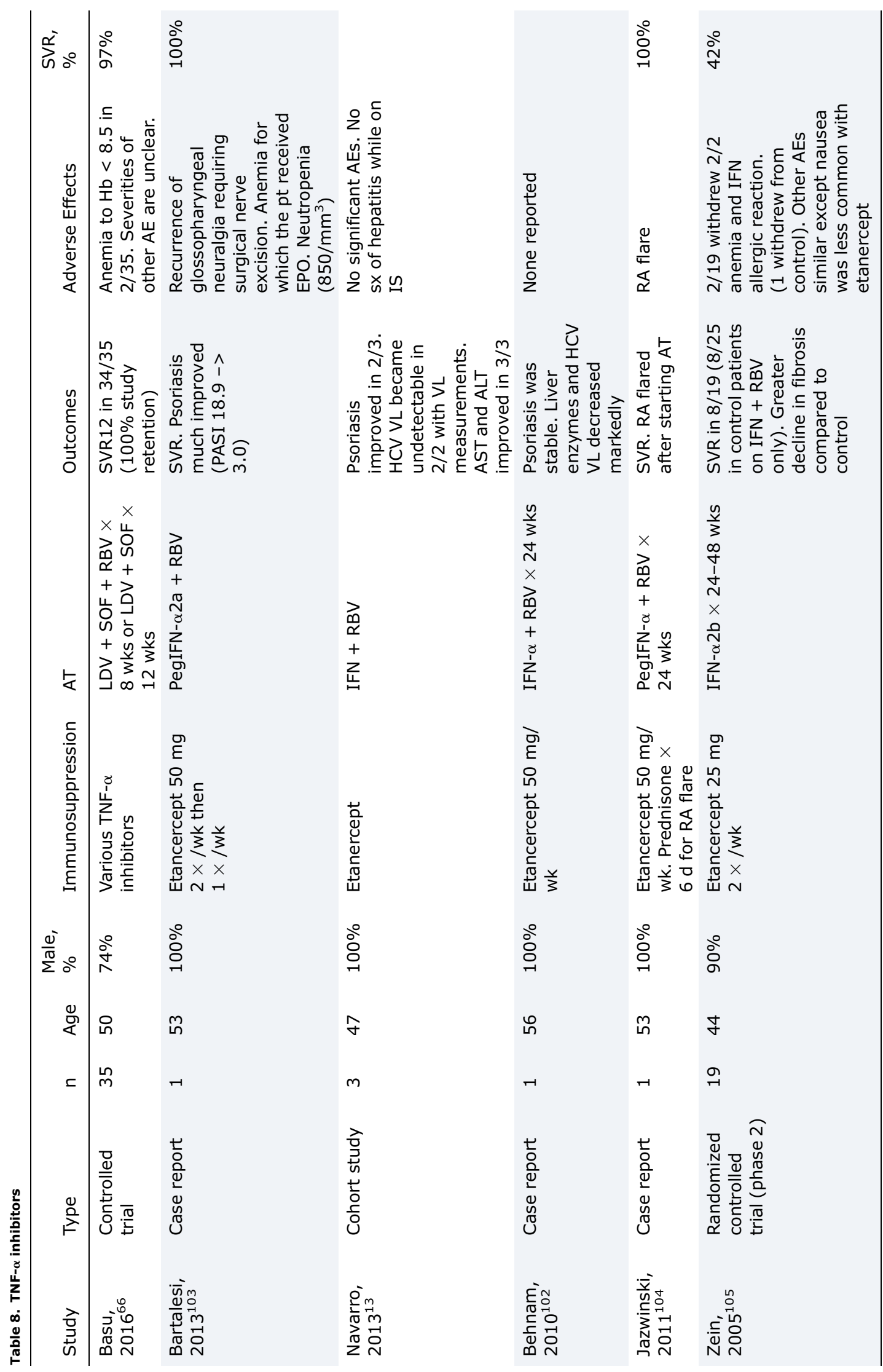


reported only in two case reports. In a report of rheumatoid arthritis treated with etanercept concomitantly with pegIFN- $\alpha$ and RBV, SVR was achieved but initiation of antiviral therapy was followed by a flare of rheumatoid arthritis that required steroids. ${ }^{104} \mathrm{~A}$ patient with psoriasis treated with etanercept concomitantly with pegIFN- $\alpha 2 a$ and RBV achieved SVR and improvement in the symptoms of psoriasis, but glossopharyngeal neuralgia recurred and required surgical nerve excision. ${ }^{103}$ Taken together, the results of these studies show that IFN-based treatments can be given to patients on TNF$\alpha$ inhibitors, but flares of underlying autoimmune diseases can occur. Moreover, one study has an outsized influence on the results due to the absence of other studies with large numbers of patients.

In an abstract addressing all-oral DAA regimens, Basu et $\mathrm{al}^{66}$ report the results of a controlled trial in which a predominantly male $(26 / 35,74 \%)$ and ethnically diverse group of patients on various TNF-inhibitors for IBD who were treated with ledipasvir and sofosbuvir for 12 weeks $(n=18)$ or in combination with RBV for 8 weeks $(n=17)$. All patients completed antiviral therapy and SVR12 was achieved in 34 of 35 total patients. Adverse effects were common and similar between the two groups, except for anemia, which was more common in the RBV group ( $8 / 17$ vs $2 / 18$ ). Overall, gastrointestinal discomfort and diarrhea were experienced by 15 and 4 patients respectively. This is an important trial both for its study design and because of the use of modern treatment regimens. Its findings should give clinicians greater confidence in administering these antiviral treatments to patients on TNF- $\alpha$ inhibitors.

\section{Antimetabolites}

Azathioprine is a purine analog and prodrug of mercaptopurine. These compounds inhibit DNA synthesis, particularly in leukocytes, and thus inhibit inflammation. ${ }^{106}$ Three studies examined the use of azathioprine in patients treated with IFNbased regimens (Table 9 ). Results were mixed. In a case series of patients with IBD, one of three patients achieved SVR and two patients required steroids for flares of Crohn's disease. ${ }^{107}$ In a case report of a 54-year-old man treated with azathioprine, prednisone, pegIFN and RBV for AIH-HCV overlap syndrome, AIH went into remission but HCV VL never reached undetectable levels. ${ }^{108}$ The patient developed respiratory failure secondary to Pseudomonal pneumonia and both immunosuppression and antiviral therapies were discontinued.

Adverse effects from concomitant use of RBV and azathioprine can be severe. In a retrospective study of eight patients on IFN, RBV and azathioprine who developed severe pancytopenia, erythropoietin (EPO), packed red blood cells and granulocyte-colony stimulating factor (G-CSF) were required in seven, two, and five patients respectively. ${ }^{109}$ Time to recovery ranged from 4 to 7 weeks.

Methotrexate inhibits the metabolism of folate, which is required for nucleoside synthesis. In addition to this canonical function, methotrexate may also exert a direct immunosuppressive effect by inhibiting cell adhesion molecules. ${ }^{110}$ One case report describes a patient treated with pegIFN- $\alpha 2 a$ and RBV while on methotrexate for rheumatoid arthritis. ${ }^{111}$ SVR was achieved but cytopenias (nadir white blood cell (WBC) count of 1.8 , platelet (PLT) count of 68,000 ) and a rheumatoid arthritis flare required the methotrexate dose to be decreased and then increased. After completion of the patient's antiviral

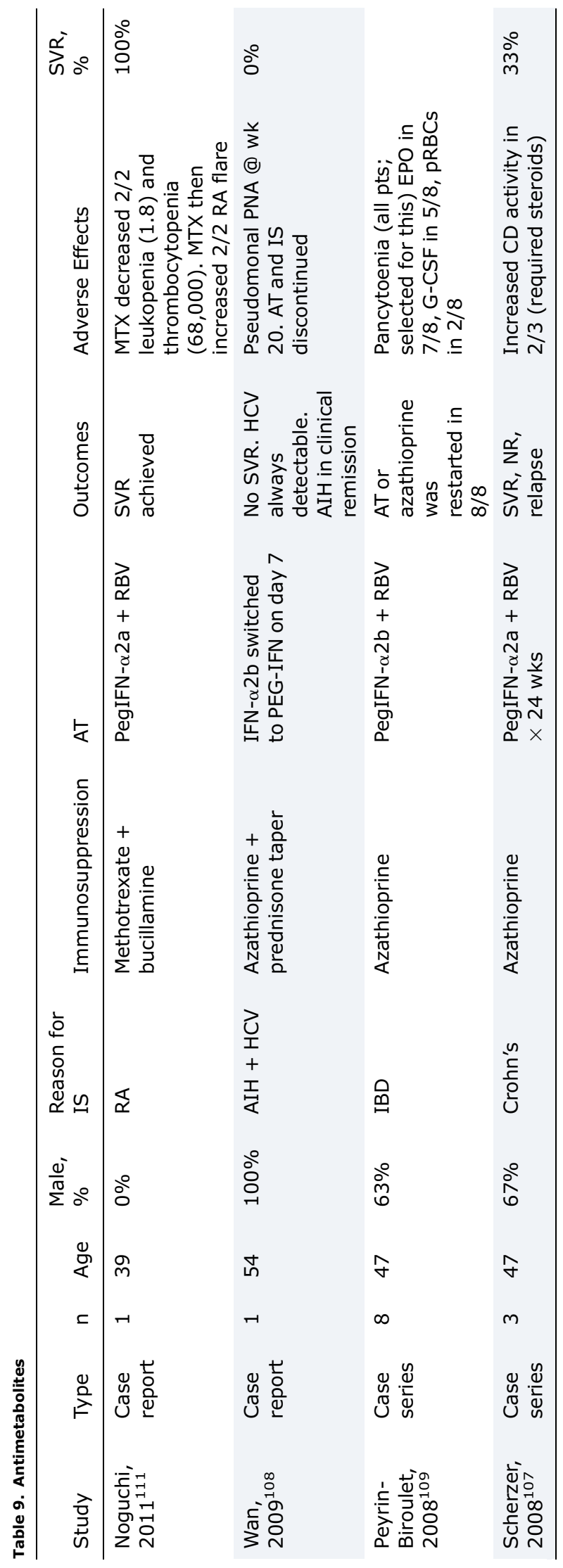




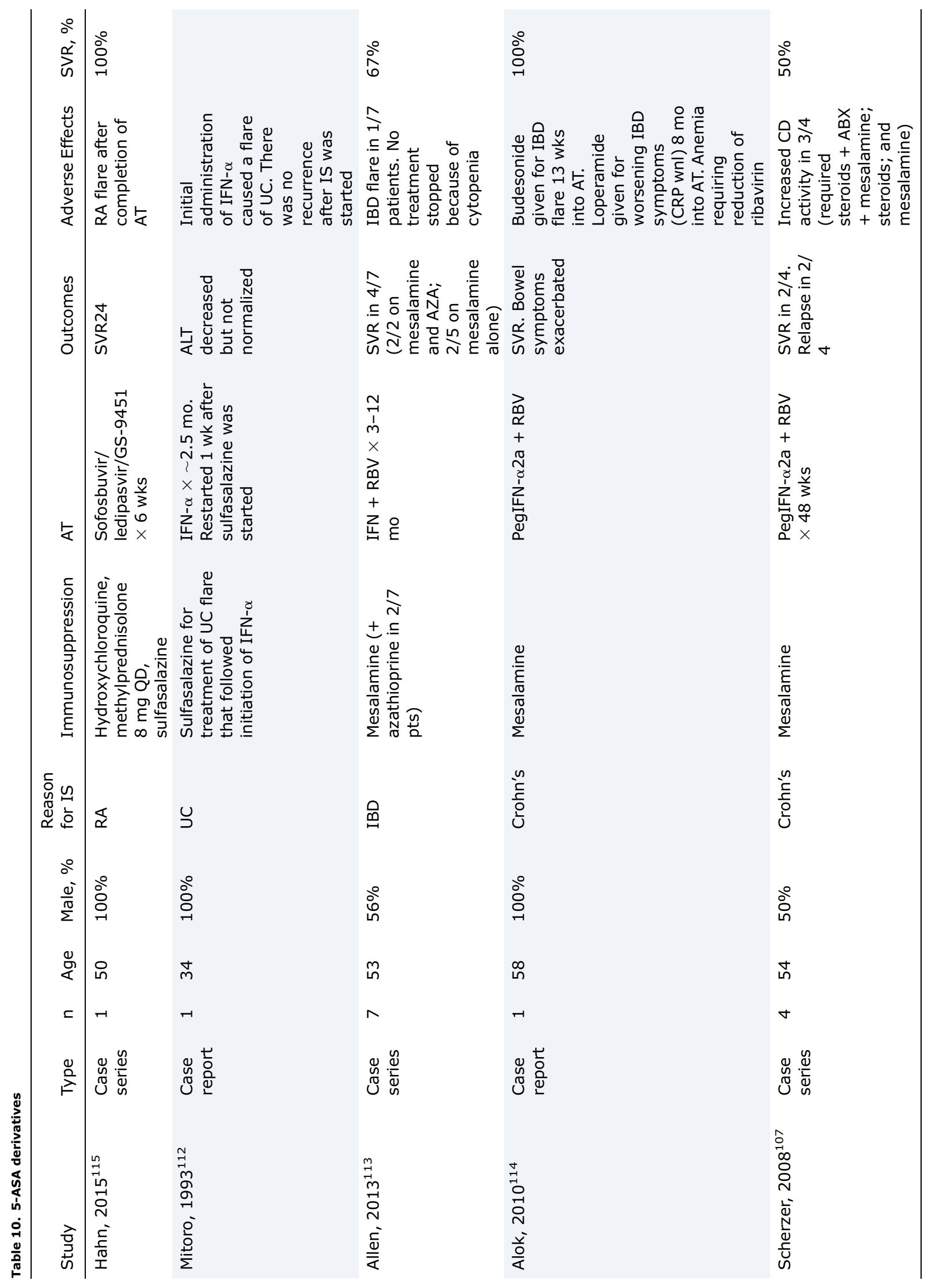


Ooka K. et al: Hepatitis C treatment in immunosuppression

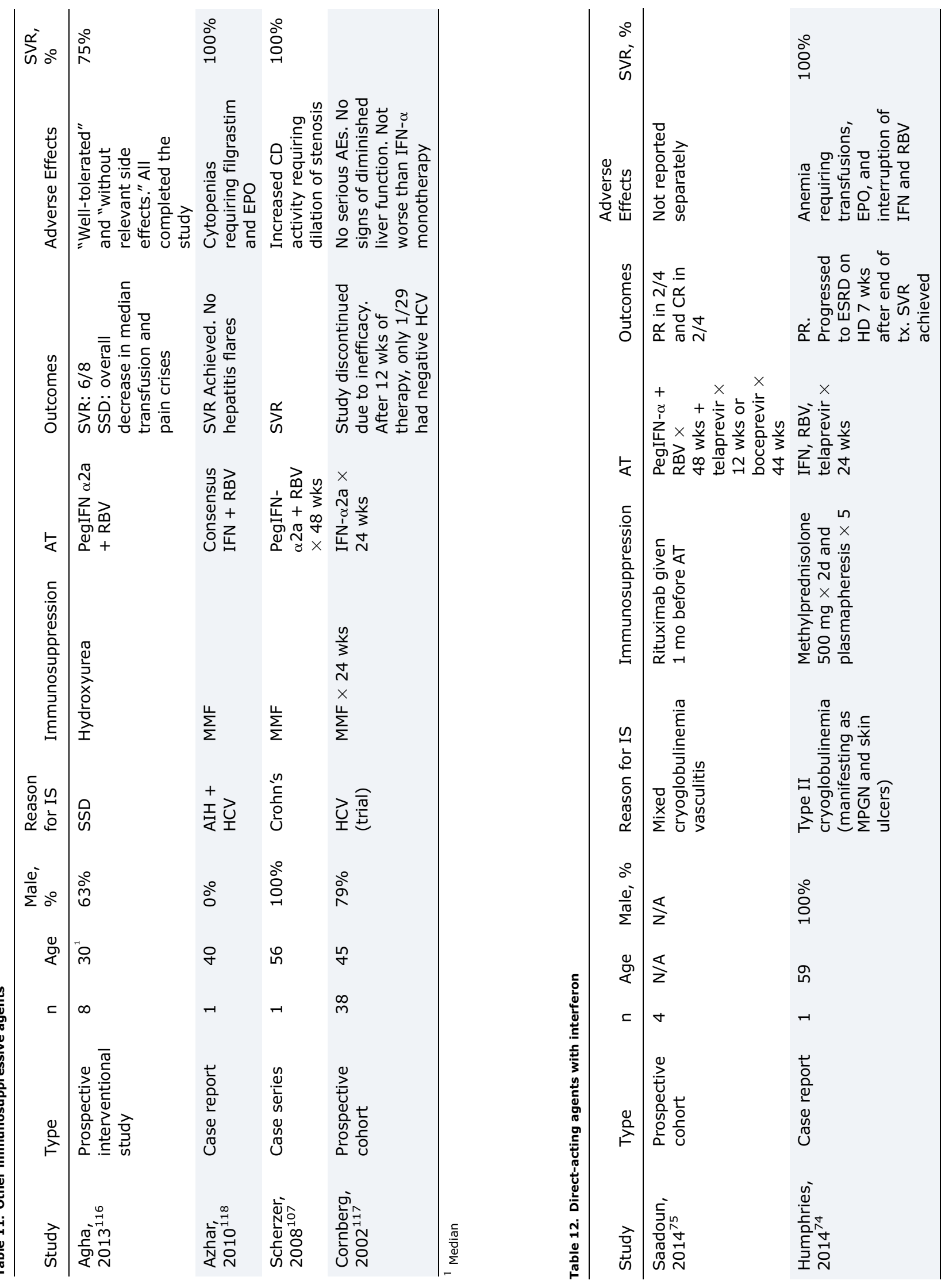




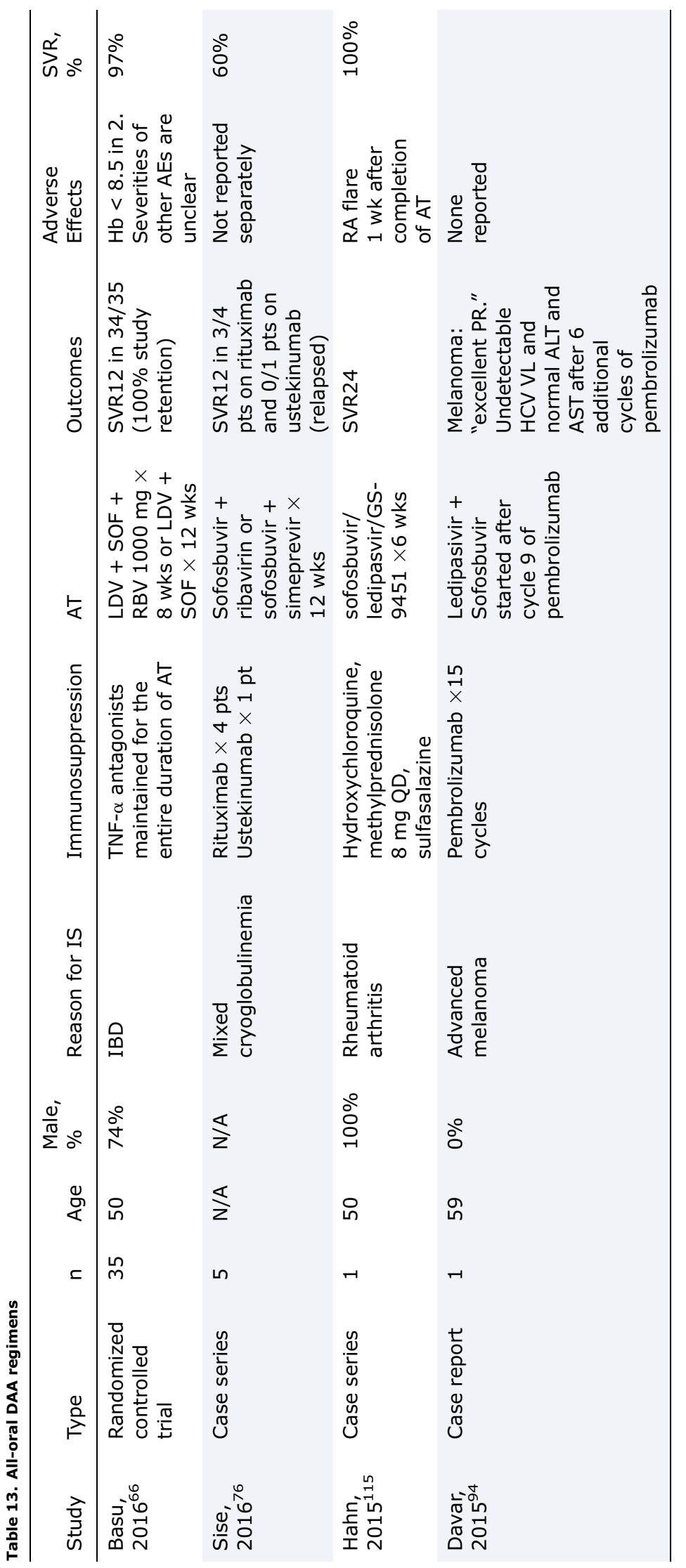


therapy, she was started on a prednisolone taper and adalimumab for worsening rheumatological symptoms.

Few conclusions can be drawn from this limited evidence base, but these cases demonstrate that SVR is feasible with IFN-based regimens, although their use may be limited by adverse effects. Data supporting the use of all-oral regimens in patients undergoing antimetabolite therapy are needed to support recommendations in this population.

\section{5-Aminosalicylic Acid (ASA) Derivatives}

Like azathioprine, the 5-ASA derivatives sulfasalazine and mesalamine are used to reduce inflammation in IBD and various autoimmune diseases, often in combination with other immunosuppressive agents. In the four studies that examined their use in patients with IBD who were undergoing IFN-based antiviral regiments, SVR was achieved in 7 of 12 patients (Table 10). ${ }^{107,112-114}$ Two of the 12 patients were also on azathioprine; both achieved SVR. One case report describes a new diagnosis of ulcerative colitis due to a flare that closely followed initiation of IFN-based antiviral therapy. ${ }^{112}$ SVR was not reported. Increased IBD activity during concomitant antiviral and immunosuppressive therapy was observed in 5 of 13 total patients. Severity of the IBD flares was variable; one patient required steroids, mesalamine and antibiotics, while another patient required budesonide.

In the setting of IBD, IFN-based antiviral therapy appears equally effective at achieving SVR. The frequency of IBD flares does seem high given that 5-ASA derivatives are typically administered for more mild disease. It would be helpful to compare the frequency of exacerbations against the frequency in patients on other agents for IBD. Unfortunately, this is limited by the sparseness of data for patients on other therapies for IBD.

One case report describes a man treated for rheumatoid arthritis with hydroxychloroquine, low-dose corticosteroids and sulfasalazine. Twenty-four weeks after a 6-week course of sofosbuvir, ledipasvir and GS-9451 (an HCV NS1 protease inhibitor), HCV VL was undetectable. ${ }^{115}$ The patient did, however, experience a flare of the rheumatoid arthritis at 1 week after completing the antiviral therapy.

Overall, the literature suggests that SVR can be achieved with all-oral DAA regimens; however, more data are needed to clarify the impact of concomitant 5-ASA treatment on treatment outcomes, and conversely the potential role of $\mathrm{HCV}$ therapy on autoimmune disease activity.

\section{Other Immunosuppressive Agents}

A number of studies report antiviral therapy used in the setting of immunosuppressant regimens that do not fit adequately within the groups above (Table 11). One single-armed interventional study of pegIFN- $\alpha 2 a$ and RBV in patients with sickle cell disease on hydroxyurea achieved SVR in 6 of 8 total patients, while transfusions and pain crises decreased. ${ }^{116}$ Adverse effects were not described in detail.

Three studies described mycophenolic acid administered concomitantly with IFN. The largest of these was a singlearmed prospective interventional trial of a 24-week course of mycophenolic acid and IFN- $\alpha 2 a$ for the treatment of chronic HCV infection in 38 previous non-responders. ${ }^{117}$ The study was discontinued after an interim analysis at 12 weeks found that only 1 of 29 patients assessed at that point had undetectable VL. No patients experienced serious adverse effects or diminished hepatic function. In a case report of mycophenolic acid administered concomitantly with consensus IFN and RBV to a patient with AIH and HCV infection, SVR was achieved. ${ }^{118}$ No hepatitis flares were observed but the patient did require filgrastim and EPO. In another study, a patient on mycophenolic acid for Crohn's disease was treated with pegIFN- $\alpha 2 a$ and RBV. ${ }^{107}$ SVR was achieved but the patient experienced increased IBD activity and required dilation of a stenotic region of bowel. Taken together, these studies show that IFN-based antiviral therapy can cause a range of side effects in patients on mycophenolate mofetil. Furthermore, as in the studies of cytotoxic chemotherapy applied as an adjunct to IFN for the treatment of $\mathrm{HCV}$, adding mycophenolate mofetil does not increase effectiveness.

\section{DAAs}

The majority of the studies in this review examine the use of historical IFN-containing regimens. However, DAAs have supplanted these regimens for the treatment of chronic HCV infection.

Two studies investigate the use of historical regimens of telaprevir or boceprevir in combination with IFN (Table 12). In four patients who had received rituximab 1 month prior for the treatment of mixed cryoglobulinemia, SVR was not reported and adverse effects were not reported separately for these patients from the larger study population in either study. ${ }^{75}$ In a patient undergoing plasmapheresis and 2 days of high-dose methylprednisolone for MPGN and skin ulcers secondary to cryoglobulinemia, SVR was achieved but renal dysfunction progressed to end-stage renal disease and severe anemia required transfusions, erythropoietin and interruption of IFN and RBV. ${ }^{74}$

Four studies examined the use of all-oral regimens in 42 patients who were on an array of immunosuppressive agents (Table 13). ${ }^{66,76,94,115}$ SVR was achieved in 38 of 41 patients $(92.6 \%)$ reportedly. Adverse effects included one patient with a flare of rheumatoid arthritis and two patients with anemia (hemoglobin, 8.5). One study describes a patient treated with ledipasvir and sofosbuvir while receiving immunotherapy for advanced melanoma; ${ }^{44}$ SVR was not reported. In general, it appears that all-oral regimens can be very effective even when patients are on immunosuppressive medications. More data in larger cohorts are needed to strengthen the evidence base for the use of all-oral DAAs in patients undergoing immunosuppressive drug therapy; although this will likely represent a preferred strategy for treatment over IFN-based regimens, which have been associated with autoimmune disease flares requiring increased immunosuppression ${ }^{104,107,111,114,115}$ and serious adverse events, including death. ${ }^{71,105,108}$

\section{Discussion}

Hepatitis $C$ is the most common chronic bloodborne infection in the United States. ${ }^{119}$ In those with acute HCV infection, approximately $80 \%$ will develop chronic hepatitis C. ${ }^{120}$ Untreated chronic infection can lead to liver fibrosis, cirrhosis, HCC, liver failure and need for liver transplant. Extra-hepatic complications include type-1 MPGN, cryoglobulinemia and vasculitis. The development of all-oral DAA regimens, which are more effective and more tolerable than IFN-based regimens, provide clinicians with the opportunity to prevent these negative outcomes in patients who are unsuitable for IFNbased therapy. Concomitant administration of immunosuppressive therapy may at first seem antithetical to the rationale 
behind IFN-based regimens; however, a growing body of evidence has been reported that supports their efficacy and safety. Trials of antiviral therapy in patients coinfected with HIV and HCV or on immunosuppressive therapy for solid organ transplant have demonstrated that treating $\mathrm{HCV}$ in immunocompromised patients can be effective at achieving SVR, albeit at lower rates than in patients with intact immune systems. ${ }^{31-34,121,122}$

While virologic relapse after SVR was seldom reported in the studies we examined, experience from coinfected patients also shows that recurrence of HCV after achieving SVR is rare. A recent systematic review of non-transplant patients who were treated and achieved SVR in the IFN era revealed a 5 -year risk of recurrence of $15 \%$, as compared to the $0.95 \%$ reported among monoinfected patients without a recognized risk factor (injection drug use, men who have sex with men or imprisonment) and the $10.67 \%$ reported among monoinfected patients with a recognized risk factor. ${ }^{123}$ However, two of the four studies of coinfected patients drew their subjects exclusively from populations with recognized risk factors (men who have sex with men and incarcerated patients). Indeed, all cases of recurrence were confirmed to be reinfection rather than late relapse. A separate study of six patients with lupus treated with pegIFN and RBV reported late relapse in two patients. ${ }^{124}$

The key limitation to the development of guideline statements addressing $\mathrm{HCV}$ treatment in patients undergoing immunosuppressive drug therapy is the poor quality of evidence, with a predominance of retrospective cohorts and case series; only eight prospective interventional trials evaluating 185 patients were identified in this systematic review. Available data strongly suggest that all-oral DAA regimens are well tolerated and associated with similar rates of SVR as those reported in patients without immunosuppression, and are unlikely to precipitate autoimmune disease activity. ${ }^{19,125}$

\section{Conclusion}

Patients on immunosuppressive therapy represent a neglected population that may stand to benefit from advances in antiviral therapy for HCV infection. While IFN-based regimens can be safe and effective in some settings, side effects are significant and efficacy is far from perfect. Furthermore, evidence is lacking in key areas, such as patients with cancer. DAAs have potential to greatly increase the number of patients treated for $\mathrm{HCV}$, but there is scant data on the use of these agents in immunosuppressed patients outside of the transplant setting. Adequately powered studies, ideally prospective observational cohort or multicenter randomized controlled trials, are needed to further strengthen the evidence base to inform guidelines on optimal all-oral treatment regimens for patients with HCV who are undergoing immunosuppressive drug therapy.

\section{Conflict of interest}

None

\section{Author contributions}

Drafting of the manuscript ( $\mathrm{KO})$, contributing to the conception and design (KO, JKL), contributing to critical revisions of the manuscript (JKL).

\section{References}

[1] Mohd Hanafiah K, Groeger J, Flaxman AD, Wiersma ST. Global epidemiology of hepatitis $C$ virus infection: new estimates of age-specific antibody to HCV seroprevalence. Hepatology 2013;57:1333-1342. doi: 10.1002/hep. 26141.

[2] The Autoimmune Diseases Coordinating Committee, National Institutes of Health. Progress in autoimmune diseases research. NIH Publication, 2005.

[3] Einav S, Koziel MJ. Immunopathogenesis of hepatitis $C$ virus in the immunosuppressed host. Transpl Infect Dis 2002;4:85-92. doi: 10.1034/j.13993062.2002.t01-2-02001.x.

[4] Schiano TD, Te HS, Thomas RM, Hussain H, Bond K, Black M. Results of steroid-based therapy for the hepatitis C-autoimmune hepatitis overlap syndrome. Am J Gastroenterol 2001;96:2984-2991. doi: 10.1111/j. 1572-0241.2001.04672.x.

[5] Fong TL, Valinluck B, Govindarajan S, Charboneau F, Adkins RH, Redeker AG. Short-term prednisone therapy affects aminotransferase activity and hepatitis C virus RNA levels in chronic hepatitis C. Gastroenterology 1994; 107:196-199. doi: 10.1016/0016-5085(94)90077-9.

[6] Magrin S, Craxi A, Fabiano C, Simonetti RG, Fiorentino G, Marino L, et al. Hepatitis $C$ viremia in chronic liver disease: relationship to interferon-alpha or corticosteroid treatment. Hepatology 1994;19:273-279. doi: 10.1002/ hep. 1840190203.

[7] Magy N, Cribier B, Schmitt C, Ellero B, Jaeck D, Boudjema K, et al. Effects of corticosteroids on HCV infection. Int J Immunopharmacol 1999;21:253261. doi: 10.1016/S0192-0561(99)00005-3.

[8] Yoshikawa M, Toyohara M, Yamane Y, Mimura M, Miyamoto Y, Ueda S, et al. Disappearance of serum HCV-RNA after short-term prednisolone therapy in a patient with chronic hepatitis $C$ associated with autoimmune hepatitislike serological manifestations. J Gastroenterol 1999;34:269-274. doi: 10. $1007 / \mathrm{s} 005350050256$.

[9] Bellary S, Schiano T, Hartman G, Black M. Chronic hepatitis with combined features of autoimmune chronic hepatitis and chronic hepatitis $C$ : favorable response to prednisone and azathioprine. Ann Intern Med 1995;123:32-34. doi: 10.7326/0003-4819-123-1-199507010-00004.

[10] Ballanti E, Conigliaro P, Chimenti MS, Kroegler B, Di Muzio G, Guarino MD et al. Use of anti-tumor necrosis factor alpha therapy in patients with concurrent rheumatoid arthritis and hepatitis B or hepatitis C: a retrospective analysis of 32 patients. Drug Dev Res 2014;75 Suppl 1:S42-S45. doi: 10. 1002/ddr.21193.

[11] Costa L, Caso F, Atteno M, Giannitti C, Spadaro A, Ramonda R, et al. Longterm safety of anti-TNF- $\alpha$ in PsA patients with concomitant HCV infection: a retrospective observational multicenter study on 15 patients. Clin Rheumatol 2014;33:273-276. doi: 10.1007/s10067-013-2378-0.

[12] Brunasso AM, Puntoni M, Gulia A, Massone C. Safety of anti-tumour necrosis factor agents in patients with chronic hepatitis $C$ infection: a systematic review. Rheumatology (Oxford) 2011;50:1700-1711. doi: 10. 1093/rheumatology/ker190.

[13] Navarro R, Vilarrasa E, Herranz P, Puig L, Bordas X, Carrascosa JM, et al. Safety and effectiveness of ustekinumab and antitumour necrosis factor therapy in patients with psoriasis and chronic viral hepatitis B or C: a retrospective, multicentre study in a clinical setting. $\mathrm{Br}$ J Dermatol 2013;168: 609-616. doi: 10.1111/bjd.12045.

[14] Loras C, Gisbert JP, Minguez M, Merino O, Bujanda L, Saro C, et al. Liver dysfunction related to hepatitis $B$ and $C$ in patients with inflammatory bowel disease treated with immunosuppressive therapy. Gut 2010;59: 1340-1346. doi: 10.1136/gut.2010.208413.

[15] Mahale P, Kontoyiannis DP, Chemaly RF, Jiang Y, Hwang JP, Davila M, et al. Acute exacerbation and reactivation of chronic hepatitis $C$ virus infection in cancer patients. J Hepatol 2012;57:1177-1185. doi: 10.1016/j.jhep.2012. 07.031.

[16] Ketikoglou I, Karatapanis S, Elefsiniotis I, Kafiri G, Moulakakis A. Extensive psoriasis induced by pegylated interferon alpha-2b treatment for chronic hepatitis B. Eur J Dermatol 2005;15:107-109.

[17] Kartal ED, Alpat SN, Ozgunes I, Usluer G. Reversible alopecia universalis secondary to PEG-interferon alpha-2b and ribavirin combination therapy in a patient with chronic hepatitis $C$ virus infection. Eur J Gastroenterol Hepatol 2007;19:817-820. doi: 10.1097/MEG.0b013e32818b27e5.

[18] Yurci A, Guven K, Torun E, Gursoy S, Baskol M, Akgun H, et al. Pyoderma gangrenosum and exacerbation of psoriasis resulting from pegylated interferon alpha and ribavirin treatment of chronic hepatitis C. Eur J Gastroenterol Hepatol 2007;19:811-815. doi: 10.1097/MEG.0b013e32816e070b.

[19] Feld JJ, Hoofnagle JH. Mechanism of action of interferon and ribavirin in treatment of hepatitis C. Nature 2005;436:967-972. doi: 10.1038/ nature04082.

[20] Cramp ME, Rossol S, Chokshi S, Carucci P, Williams R, Naoumov NV. Hepatitis C virus-specific T-cell reactivity during interferon and ribavirin treatment in chronic hepatitis C. Gastroenterology 2000;118:346-355. doi: 10.1016/S0016-5085(00)70217-4. 
[21] Cooper S, Erickson AL, Adams EJ, Kansopon J, Weiner AJ, Chien DY, et al. Analysis of a successful immune response against hepatitis $C$ virus. Immunity 1999;10:439-449. doi: 10.1016/S1074-7613(00)80044-8.

[22] Shoukry NH, Grakoui A, Houghton M, Chien DY, Ghrayeb J, Reimann KA, et al. Memory CD8+ T cells are required for protection from persistent hepatitis C virus infection. J Exp Med 2003;197:1645-1655. doi: 10. 1084/jem. 20030239.

[23] Grakoui A, Shoukry NH, Woollard DJ, Han JH, Hanson HL, Ghrayeb J, et al. $\mathrm{HCV}$ persistence and immune evasion in the absence of memory T cell help. Science 2003;302:659-662. doi: 10.1126/science.1088774.

[24] Ahlenstiel G, Titerence RH, Koh C, Edlich B, Feld J], Rotman Y, et al. Natural killer cells are polarized toward cytotoxicity in chronic hepatitis $C$ in an interferon-alfa-dependent manner. Gastroenterology 2010;138:325-335. e321-322.

[25] Heim MH. 25 years of interferon-based treatment of chronic hepatitis C: an epoch coming to an end. Nat Rev Immunol 2013;13:535-542. doi: 10. $1038 / \mathrm{nri3463.}$

[26] Schoggins JW, Wilson SJ, Panis M, Murphy MY, Jones CT, Bieniasz P, et al. A diverse range of gene products are effectors of the type I interferon antiviral response. Nature 2011;472:481-485. doi: 10.1038/nature09907.

[27] Everson GT. Impact of immunosuppressive therapy on recurrence of hepatitis C. Liver Transpl 2002;8:S19-S27. doi: 10.1053/jlts.2002.35852.

[28] Vento S, Cainelli F, Mirandola F, Cosco L, Di Perri G, Solbiati M, et al. Fulminant hepatitis on withdrawal of chemotherapy in carriers of hepatitis $C$ virus. Lancet 1996;347:92-93. doi: 10.1016/S0140-6736(96)90212-3.

[29] Nakamura Y, Motokura T, Fujita A, Yamashita T, Ogata E. Severe hepatitis related to chemotherapy in hepatitis B virus carriers with hematologic malignancies. Survey in Japan, 1987-1991. Cancer 1996;78:2210-2215. doi: 10.1002/(SICI)1097-0142(19961115)78:10<2210::AID-CNCR24>3. $0 . \mathrm{CO} ; 2-0$.

[30] Fan FS, Tzeng CH, Hsiao KI, Hu ST, Liu WT, Chen PM. Withdrawal of immunosuppressive therapy in allogeneic bone marrow transplantation reactivates chronic viral hepatitis C. Bone Marrow Transplant 1991;8:417-420.

[31] Kwo PY, Mantry PS, Coakley E, Te HS, Vargas HE, Brown R Jr, et al. An interferon-free antiviral regimen for $\mathrm{HCV}$ after liver transplantation. $\mathrm{N}$ Engl J Med 2014;371:2375-2382. doi: 10.1056/NEJMoa1408921.

[32] Ciesek S, Proske V, Otto B, Pischke S, Costa R, Lüthgehetmann M, et al. Efficacy and safety of sofosbuvir/ledipasvir for the treatment of patients with hepatitis $C$ virus re-infection after liver transplantation. Transpl Infect Dis 2016;18:326-332. doi: 10.1111/tid.12524.

[33] Manns M, Samuel D, Gane EJ, Mutimer D, McCaughan G, Buti M, et al. Ledipasvir and sofosbuvir plus ribavirin in patients with genotype 1 or 4 hepatitis C virus infection and advanced liver disease: a multicentre, open-label, randomised, phase 2 trial. Lancet Infect Dis 2016;16:685697. doi: $10.1016 / \mathrm{S} 1473-3099(16) 00052-9$.

[34] Poordad F, Schiff ER, Vierling JM, Landis C, Fontana RJ, Yang R, et al. Daclatasvir with sofosbuvir and ribavirin for Hepatitis $C$ virus infection with advanced cirrhosis or post-liver transplantation recurrence. Hepatology 2016;63:1493-1505. doi: 10.1002/hep.28446.

[35] Strader DB, Wright T, Thomas DL, Seeff LB, American Association for the Study of Liver Diseases. Diagnosis, management, and treatment of hepatitis C. Hepatology 2004;39:1147-1171. doi: 10.1002/hep.20119.

[36] Lauer GM, Walker BD. Hepatitis C virus infection. N Engl ] Med 2001;345: 41-52. doi: 10.1056/NEJM200107053450107.

[37] Andriani A, Bibas M, Callea V, De Renzo A, Chiurazzi F, Marcenò R, et al. Autoimmune hemolytic anemia during alpha interferon treatment in nine patients with hematological diseases. Haematologica 1996;81:258-260.

[38] Fernandez-Soto L, Gonzalez A, Escobar-Jimenez F, Vazquez R, Ocete E, Olea $\mathrm{N}$, et al. Increased risk of autoimmune thyroid disease in hepatitis $\mathrm{C}$ vs hepatitis $B$ before, during, and after discontinuing interferon therapy. Arch Intern Med 1998;158:1445-1448. doi: 10.1001/archinte.158.13.1445.

[39] García-Buey L, García-Monzón C, Rodriguez S, Borque MJ, García-Sánchez A, Iglesias $R$, et al. Latent autoimmune hepatitis triggered during interferon therapy in patients with chronic hepatitis C. Gastroenterology $1995 ; 108$ : 1770-1777. doi: 10.1016/0016-5085(95)90139-6.

[40] Cacoub P, Ouzan D, Melin P, Lang JP, Rotily M, Fontanges T, et al. Patient education improves adherence to peg-interferon and ribavirin in chronic genotype 2 or 3 hepatitis $C$ virus infection: a prospective, real-life, observational study. World J Gastroenterol 2008;14:6195-6203. doi: 10.3748/ wjg.14.6195.

[41] Zhu GQ, Zou ZL, Zheng JN, Chen DZ, Zou TT, Shi KQ, et al. Systematic review and network meta-analysis of randomized controlled trials: comparative effectiveness and safety of direct-acting antiviral agents for treatment-naive hepatitis C genotype 1. Medicine (Baltimore) 2016;95: e3004. doi: 10.1097/MD.0000000000003004.

[42] Gutierrez JA, Lawitz EJ, Poordad F. Interferon-free, direct-acting antiviral therapy for chronic hepatitis C. J Viral Hepat 2015;22:861-870. doi: 10. $1111 /$ jvh. 12422.
[43] Banerjee D, Reddy KR. Review article: safety and tolerability of direct-acting anti-viral agents in the new era of hepatitis $C$ therapy. Aliment Pharmacol Ther 2016;43:674-696. doi: 10.1111/apt.13514.

[44] Charlton M, Everson GT, Flamm SL, Kumar P, Landis C, Brown RS Jr, et al. Ledipasvir and sofosbuvir plus ribavirin for treatment of HCV infection in patients with advanced liver disease. Gastroenterology 2015;149:649659. doi: 10.1053/j.gastro.2015.05.010.

[45] Wyles DL, Rodriguez-Torres M, Lawitz E, Shiffman ML, Pol S, Herring RW, et al. All-oral combination of ledipasvir, vedroprevir, tegobuvir, and ribavirin in treatment-naive patients with genotype $1 \mathrm{HCV}$ infection. Hepatology 2014;60:56-64. doi: 10.1002/hep.27053.

[46] Zeuzem S, Berg T, Gane E, Ferenci P, Foster GR, Fried MW, et al. Simeprevir increases rate of sustained virologic response among treatmentexperienced patients with HCV genotype-1 infection: a phase IIb trial. Gastroenterology 2014;146:430-441 e436.

[47] Sulkowski MS, Eron J], Wyles D, Trinh R, Lalezari J, Wang C, et al. Ombitasvir, paritaprevir co-dosed with ritonavir, dasabuvir, and ribavirin for hepatitis $\mathrm{C}$ in patients co-infected with HIV-1: a randomized trial. JAMA 2015;313:1223-1231. doi: 10.1001/jama.2015.1328.

[48] Wang CS, Ko HH, Yoshida EM, Marra CA, Richardson K. Interferon-based combination anti-viral therapy for hepatitis $C$ virus after liver transplantation: a review and quantitative analysis. Am J Transplant 2006;6:15861599. doi: 10.1111/j.1600-6143.2006.01362.x.

[49] Chalasani N, Manzarbeitia C, Ferenci P, Vogel W, Fontana RJ, Voigt M, et al. Peginterferon alfa-2a for hepatitis $\mathrm{C}$ after liver transplantation: two randomized, controlled trials. Hepatology 2005;41:289-298. doi: 10.1002/hep. 20560.

[50] Oton E, Barcena R, Moreno-Planas JM, Cuervas-Mons V, Moreno-Zamora A, Barrios $C$, et al. Hepatitis $C$ recurrence after liver transplantation: Viral and histologic response to full-dose PEG-interferon and ribavirin. Am J Transplant 2006;6:2348-2355. doi: 10.1111/j.1600-6143.2006.01470.x.

[51] Neumann U, Puhl G, Bahra M, Berg T, Langrehr JM, Neuhaus R, et al. Treatment of patients with recurrent hepatitis $C$ after liver transplantation with peginterferon alfa-2B plus ribavirin. Transplantation 2006;82:43-47. doi: 10.1097/01.tp.0000225827.18034.be.

[52] Angelico M, Petrolati A, Lionetti R, Lenci I, Burra P, Donato MF, et al. A randomized study on Peg-interferon alfa-2a with or without ribavirin in liver transplant recipients with recurrent hepatitis C. J Hepatol 2007;46: 1009-1017. doi: 10.1016/j.jhep.2006.12.017.

[53] Samuel D, Bizollon T, Feray C, Roche B, Ahmed SN, Lemonnier C, et al. Interferon-alpha $2 \mathrm{~b}$ plus ribavirin in patients with chronic hepatitis $C$ after liver transplantation: a randomized study. Gastroenterology 2003;124: 642-650. doi: 10.1053/gast.2003.50095.

[54] Available at: http://www.hcvguidelines.org.

[55] Poordad F, Schiff ER, Vierling JM, Landis C, Fontana RJ, Yang R, et al. Daclatasvir with sofosbuvir and ribavirin for hepatitis $C$ virus infection with advanced cirrhosis or post-liver transplantation recurrence. Hepatology 2016;63:1493-1505. doi: 10.1002/hep.28446.

[56] Fontana RJ, Brown RS Jr, Moreno-Zamora A, Prieto M, Joshi S, Londoño MC, et al. Daclatasvir combined with sofosbuvir or simeprevir in liver transplant recipients with severe recurrent hepatitis C infection. Liver Transpl 2016; 22:446-458. doi: 10.1002/lt.24416.

[57] Fabrizi F, Penatti A, Messa P, Martin P. Treatment of hepatitis C after kidney transplant: a pooled analysis of observational studies. J Med Virol 2014;86: 933-940. doi: 10.1002/jmv.23919.

[58] Kidney Disease: Improving Global Outcomes (KDIGO) Transplant Work Group. KDIGO clinical practice guideline for the care of kidney transplant recipients. Am J Transplant 2009;9 Suppl 3:S1-S155. doi: 10.1111/j.16006143.2009.02834.x.

[59] Huard G, Kim B, Patel A, Aljarallah B, Perumalswami P, Odin JA, et al. Early safety and efficacy profiles of Renal Transplant Recipients with chronic hepatitis C treated with Sofosbuvir and Ribavirin. The 65th Annual Meeting of the American Association for the Study of Liver Diseases: The Liver Meeting 2014. Boston, Massachusetts 2014.

[60] Lin MV, Sise ME, Pavlakis M, Hanifi JM, Rutherford AE, Elias N, et al. LP42: Safety and efficacy of novel antivirals in kidney transplant recipients with chronic hepatitis c virus (HCV) infection. J Hepatol 2015;62:S284-S285. doi: 10.1016/S0168-8278(15)30196-3.

[61] Bonacci M, Londoño MC, Esforzado N, Forns X, Sotoca JM, Campistol JM. Antiviral treatment with sofosbuvir and simeprevir in a kidney transplant recipient with HCV-decompensated cirrhosis: viral eradication and removal from the liver transplant waiting list. Transpl Int 2015;28:13451349. doi: $10.1111 /$ tri.12622.

[62] Kamar N, Marion O, Rostaing L, Cointault O, Ribes D, Lavayssière L, et al. Efficacy and safety of sofosbuvir-based antiviral therapy to treat hepatitis C virus infection after kidney transplantation. Am J Transplant 2016;16:1474-1479. doi: 10.1111/ajt.13518.

[63] Colombo M, Aghemo A, Liu H, Dvory-Sobol H, Hyland RH, Yun C, et al. Ledipasvir/Sofosbuvir (LDV/SOF) for 12 or 24 Weeks Is Safe and Effective 
in Kidney Transplant Recipients with Chronic Genotype 1 or 4 HCV Infection. International Liver Congress. Barcelona, Spain 2016.

[64] Giardini C, Galimberti M, Lucarelli G, Polchi P, Angelucci E, Baronciani D, et al. Alpha-interferon treatment of chronic hepatitis $\mathrm{C}$ after bone marrow transplantation for homozygous beta-thalassemia. Bone Marrow Transplant 1997; 20:767-772. doi: 10.1038/sj.bmt.1700968.

[65] Varma A, Saliba RM, Torres HA, Afrough A, Hosing C, Khouri IF, et al. Outcomes in hepatitis $C$ virus seropositive lymphoma and myeloma patients after autologous stem cell transplantation. Bone Marrow Transplant 2016; 51:999-1001. doi: 10.1038/bmt.2016.28.

[66] Basu P. Sofosbuvir, Ledipasvir in IBD treated patients with advanced biologics including Ribavirin eradicating Chronic Hepatitis C: SOLATAIRE C Trial. A multi-center clinical prospective pilot study. APASL 2016:2016.

[67] Dustin LB, Rice CM. Flying under the radar: the immunobiology of hepatitis C. Annu Rev Immunol 2007;25:71-99. doi: 10.1146/annurev.immunol.25. 022106.141602.

[68] Dammacco F, Sansonno D. Therapy for hepatitis C virus-related cryoglobulinemic vasculitis. N Engl J Med 2013;369:1035-1045. doi: 10.1056/ NEJMra1208642.

[69] Pietrogrande M, De Vita S, Zignego AL, Pioltelli P, Sansonno D, Sollima S, et al. Recommendations for the management of mixed cryoglobulinemia syndrome in hepatitis C virus-infected patients. Autoimmun Rev 2011;10: 444-454. doi: 10.1016/j.autrev.2011.01.008.

[70] Saadoun D, Delluc A, Piette JC, Cacoub P. Treatment of hepatitis C-associated mixed cryoglobulinemia vasculitis. Curr Opin Rheumato 2008;20:23-28. doi: 10.1097/bor.0b013e3282f1330c.

[71] Saadoun D, Resche Rigon M, Sene D, Terrier B, Karras A, Perard L, et al. Rituximab plus Peg-interferon-alpha/ribavirin compared with Peginterferon-alpha/ribavirin in hepatitis C-related mixed cryoglobulinemia. Blood 2010;116:326-334; quiz 504-505. doi: 10.1182/blood-2009-10248518.

[72] Dammacco F, Tucci FA, Lauletta G, Gatti P, De Re V, Conteduca V, et al. Pegylated interferon-alpha, ribavirin, and rituximab combined therapy of hepatitis C virus-related mixed cryoglobulinemia: a long-term study. Blood 2010;116:343-353. doi: 10.1182/blood-2009-10-245878.

[73] Terrier B, Saadoun D, Sène D, Sellam J, Pérard L, Coppéré B, et al. Efficacy and tolerability of rituximab with or without PEGylated interferon alfa-2b plus ribavirin in severe hepatitis $C$ virus-related vasculitis: a long-term followup study of thirty-two patients. Arthritis Rheum 2009;60: 2531-2540. doi: 10.1002/art.24703.

[74] Humphries K, Darling JM, Barritt AS 4th. Membranoproliferative glomerulonephritis, type II cryoglobulinemia and triple therapy for hepatitis C: a case series and review of the literature. Dig Dis Sci 2014;59:2007-2012. doi: 10.1007/s10620-014-3085-7.

[75] Saadoun D, Resche Rigon M, Thibault V, Longuet M, Pol S, Blanc F, et al. PegIFN $\alpha$ /ribavirin/protease inhibitor combination in hepatitis $C$ virus associated mixed cryoglobulinemia vasculitis: results at week 24 . Ann Rheum Dis 2014;73:831-837. doi: 10.1136/annrheumdis-2012-202770.

[76] Sise ME, Bloom AK, Wisocky J, Lin MV, Gustafson JL, Lundquist AL, et al. Treatment of hepatitis $C$ virus-associated mixed cryoglobulinemia with direct-acting antiviral agents. Hepatology 2016;63:408-417. doi: 10. 1002/hep.28297.

[77] Coutinho AE, Chapman KE. The anti-inflammatory and immunosuppressive effects of glucocorticoids, recent developments and mechanistic insights. Mol Cell Endocrinol 2011;335:2-13. doi: 10.1016/j.mce.2010.04.005.

[78] McHutchison JG, Ponnudurai R, Bylund DL, Anguiano A, Pockros PJ, Mondala T, et al. Prednisone withdrawal followed by interferon alpha for treatment of chronic hepatitis $\mathrm{C}$ infection: results of a randomized controlled trial. J Clin Gastroenterol 2001;32:133-137. doi: 10.1097/00004836-20010200000008.

[79] Liaw YF, Sheen IS, Lin SM, Chen TJ, Chu CM. Effects of prednisolone pretreatment in interferon alfa therapy for patients with chronic non-A non-B (C) hepatitis. Liver 1993;13:46-50. doi: 10.1111/j.1600-0676. 1993.tb00604.x.

[80] Guilera M, Forns X, Torras X, Enriquez ], Coll S, Solà R, et al. Pre-treatment with prednisolone does not improve the efficacy of subsequent alpha interferon therapy in chronic hepatitis C. J Hepatol 2000;33:135-141. doi: 10. 1016/S0168-8278(00)80170-1.

[81] Wu H, Zou HB, Xu Y, Zhang L, Du YJ, Yu JY, et al. Hepatitis C virus-related heat-insoluble cryoglobulinemia and thrombotic microangiopathy. Am J Med Sci 2013;346:345-348. doi: 10.1097/MAJ.0b013e318293cdee.

[82] Kiremitci S, Calayoglu R, Ensari A, Erbay B. Pathologist's puzzle: Membranoproliferative glomerulonephritis-like features in cryoglobulinemic glomerulonephritis. Pathol Res Pract 2012;208:254-258. doi: 10.1016/j.prp. 2012.01.006.

[83] Ahmed MS, Wong CF, Shawki H, Kapoor N, Pandya BK. Rapidly deteriorating renal function with membranoproliferative glomerulonephritis Type 1 associated with hepatitis C treated successfully with steroids and antiviral therapy: a case report and review of literature. Clin Nephrol 2008;69: 298-301. doi: 10.5414/CNP69298.
[84] Mercié $P$, Viallard JF, Faure I, Trimoulet $P$, Vital A, Lifermann F, et al. Hepatitis $C$ virus infection with and without cryoglobulinemia as a case of ChurgStrauss syndrome. J Rheumatol 2000;27:814-817.

[85] Oeda S, Mizuta T, Isoda H, Kuwashiro T, Oza N, Iwane S, et al. Efficacy of pegylated interferon plus ribavirin in combination with corticosteroid for two cases of combined hepatitis C and autoimmune hepatitis. Clin J Gastroenterol 2012;5:141-145. doi: 10.1007/s12328-012-0295-4.

[86] Efe C, Heurgué-Berlot A, Ozaslan E, Purnak T, Thiéfin G, Simsek H, et al. Late autoimmune hepatitis after hepatitis C therapy. Eur J Gastroenterol Hepatol 2013;25:1308-1311. doi: 10.1097/MEG.0b013e328361c704.

[87] Edwards BK, Noone AM, Mariotto AB, Simard EP, Boscoe FP, Henley S], et al. Annual Report to the Nation on the status of cancer, 1975-2010, featuring prevalence of comorbidity and impact on survival among persons with lung, colorectal, breast, or prostate cancer. Cancer 2014;120:1290-1314. doi: 10.1002/cncr.28509.

[88] Torres HA, Mahale P, Blechacz B, Miller E, Kaseb A, Herlong HF, et al. Effect of hepatitis $C$ virus infection in patients with cancer: addressing a neglected population. J Natl Compr Canc Netw 2015;13:41-50.

[89] Allison RD, Tong X, Moorman AC, Ly KN, Rupp L, Xu F, et al. Increased incidence of cancer and cancer-related mortality among persons with chronic hepatitis C infection, 2006-2010. J Hepatol 2015;63:822-828. doi: 10.1016/j.jhep.2015.04.021.

[90] Kasai K, Kuroda H, Ushio A, Sawara K, Takikawa Y, Suzuki K. Evaluation of newly developed combination therapy of intra-arterial 5 -fluorouracil and systemic pegylated interferon alpha-2b for advanced hepatocellular carcinoma with portal venous invasion: preliminary results. Hepatol Res 2009; 39:117-125. doi: 10.1111/j.1872-034X.2008.00414.x.

[91] Lakatos PL, Fekete S, Horanyi M, Fischer S, Abonyi ME. Development of multiple myeloma in a patient with chronic hepatitis C: A case report and review of the literature. World J Gastroenterol 2006;12:2297-2300. doi: 10.3748/wjg.v12.i14.2297.

[92] Matovina-Brko G, Ruzic M, Fabri M, Popovic L, Kolarov-Bjelobrk I, Trifunovic J, et al. Treatment of acute hepatitis C in breast cancer patient: a case report. J Chemother 2014;26:180-183. doi: 10.1179/1973947813Y. 0000000129.

[93] Kyvernitakis A, Duvic M, Mahale P, Torres HA. Interferon-based treatment for patients with mycosis fungoides and hepatitis $C$ virus infection: a case series. Am J Clin Dermatol 2014;15:451-456. doi: 10.1007/s40257-0140084-6.

[94] Davar D, Wilson M, Pruckner C, Kirkwood JM. PD-1 blockade in advanced melanoma in patients with hepatitis $C$ and/or HIV. Case Rep Oncol Med 2015;2015:737389. doi: 10.1155/2015/737389.

[95] Inoue K, Sekiyama K, Yamada M, Watanabe T, Yasuda H, Yoshiba M. Combined interferon $\alpha 2 b$ and cyclosporin $A$ in the treatment of chronic hepatitis C: controlled trial. Reumatismo 2005; 57:128-129.

[96] Cotler SJ, Morrissey MJ, Wiley TE, Layden TJ, Jensen DM. A pilot study of the combination of cyclosporin A and interferon alfacon-1 for the treatment of hepatitis C in previous nonresponder patients. J Clin Gastroenterol 2003; 36:352-355. doi: 10.1097/00004836-200304000-00014.

[97] Pardo M, Castillo I, Navas S, Carreño V. Treatment of chronic hepatitis C with cirrhosis with recombinant human granulocyte colony-stimulating factor plus recombinant interferon-alpha. J Med Virol 1995;45:439-444. doi: $10.1002 / j m v .1890450415$.

[98] Pompili M, Biolato M, Miele L, Grieco A. Tumor necrosis factor- $\alpha$ inhibitors and chronic hepatitis $C$ : a comprehensive literature review. World J Gastroenterol 2013;19:7867-7873. doi: 10.3748/wjg.v19.i44.7867.

[99] Bongartz T, Sutton AJ, Sweeting MJ, Buchan I, Matteson EL, Montori V. AntiTNF antibody therapy in rheumatoid arthritis and the risk of serious infections and malignancies: systematic review and meta-analysis of rare harmful effects in randomized controlled trials. JAMA 2006;295:22752285. doi: 10.1001/jama.295.19.2275.

[100] Costenbader KH, Glass R, Cui J, Shadick N. Risk of serious infections and malignancies with anti-TNF antibody therapy in rheumatoid arthritis. JAMA 2006;296:2201; author reply 2203-2204. doi: 10.1001/jama.296.18. 2202.

[101] Breedveld FC, Weisman MH, Kavanaugh AF, Cohen SB, Pavelka K, van Vollenhoven R, et al. The PREMIER study: A multicenter, randomized, double-blind clinical trial of combination therapy with adalimumab plus methotrexate versus methotrexate alone or adalimumab alone in patients with early, aggressive rheumatoid arthritis who had not had previous methotrexate treatment. Arthritis Rheum 2006;54:26-37. doi: 10.1002/ art.21519.

[102] Behnam SE, Hindiyeh R, Fife DJ, Jeffes EW 3rd, Wu JJ. Etanercept as prophylactic psoriatic therapy before interferon-alpha and ribavirin treatment for active hepatitis C infection. Clin Exp Dermatol 2010;35:397-398. doi: 10.1111/j.1365-2230.2009.03476.x.

[103] Bartalesi F, Salomoni E, Cavallo A, Corti G, Pimpinelli N, Bartoloni A, et al. Chronic hepatitis $C$ virus hepatitis and psoriasis: no longer a contraindication to interferon use in the era of biological agents? Scand J Infect Dis 2013;45:320-323. doi: 10.3109/00365548.2012.720026. 
[104] Jazwinski AB, Jezsik J, Ardoin SP, McCallum RM, Tillmann HL. Etanercept treatment to enable successful hepatitis $C$ virus clearance in a patient with rheumatoid arthritis. Gastroenterol Hepatol (N Y) 2011;7:772-774.

[105] Zein NN, Etanercept Study Group. Etanercept as an adjuvant to interferon and ribavirin in treatment-naive patients with chronic hepatitis $\mathrm{C}$ virus infection: a phase 2 randomized, double-blind, placebo-controlled study. J Hepatol 2005;42:315-322. doi: 10.1016/j.jhep.2004.11.025.

[106] Maltzman JS, Koretzky GA. Azathioprine: old drug, new actions. J Clin Invest 2003;111:1122-1124. doi: 10.1172/JCI200318384.

[107] Scherzer TM, Staufer K, Novacek G, Steindl-Munda P, Schumacher S, Hofer $\mathrm{H}$, et al. Efficacy and safety of antiviral therapy in patients with Crohn's disease and chronic hepatitis C. Aliment Pharmacol Ther 2008;28:742748. doi: 10.1111/j.1365-2036.2008.03779.x.

[108] Wan DW, Marks K, Yantiss RK, Talal AH. Autoimmune hepatitis in the HIVinfected patient: a therapeutic dilemma. AIDS Patient Care STDS 2009;23: 407-413. doi: 10.1089/apc.2008.0149.

[109] Peyrin-Biroulet L, Cadranel JF, Nousbaum JB, Oussalah A, Seddik M, Canva $\mathrm{V}$, et al. Interaction of ribavirin with azathioprine metabolism potentially induces myelosuppression. Aliment Pharmacol Ther 2008;28:984-993. doi: $10.1111 / j .1365-2036.2008 .03812 . x$

[110] Wessels JA, Huizinga TW, Guchelaar HJ. Recent insights in the pharmacological actions of methotrexate in the treatment of rheumatoid arthritis. Rheumatology (Oxford) 2008;47:249-255. doi: 10.1093/rheumatology/kem279.

[111] Noguchi O, Gibo Y. Induction of clinical remission with adalimumabmethotrexate combination therapy in a patient with rheumatoid arthritis and concomitant hepatitis C virus infection. Mod Rheumatol 2011;21: 696-700. doi: 10.3109/s10165-011-0469-9.

[112] Mitoro A, Yoshikawa M, Yamamoto K, Mimura M, Yoshikawa Y, Shiroi A, et al. Exacerbation of ulcerative colitis during alpha-interferon therapy for chronic hepatitis C. Intern Med 1993;32:327-331. doi: 10.2169/internalmedicine. 32.327.

[113] Allen AM, Kim WR, Larson J, Loftus EV Jr. Efficacy and safety of treatment of hepatitis $C$ in patients with inflammatory bowel disease. Clin Gastroenterol Hepatol 2013;11:1655-1660. e1651.

[114] Gupta A, Sitrin MD. Concomitant therapy of Crohn's disease and hepatitis C with budesonide and antivirals. Gastroenterol Hepatol (N Y) 2010;6:525527.

[115] Hahn KJ, Kohli A, Sims Z, Kottilil S. Durable sustained virologic response after oral directly acting antiviral therapy despite immunosuppressive treatment. Open Forum Infect Dis 2015;2:ofv091.

[116] Agha A, Chakik R, Abdulhadi Ali MM, Alsaudi D, Sammito G, Giannini EG. Peg-interfon alpha-2a and low-dose ribavirin for treatment of hepatitis $C$ virus infection in patients with sickle-cell anemia in Saudi Arabia. Ann Saudi Med 2013;33:610-613.

[117] Cornberg M, Hinrichsen H, Teuber G, Berg T, Naumann U, Falkenberg C, et al. Mycophenolate mofetil in combination with recombinant interferon alfa-2a in interferon-nonresponder patients with chronic hepatitis $\mathrm{C}$. J Hepatol 2002;37:843-847. doi: 10.1016/S0168-8278(02)00300-8.

[118] Azhar A, Niazi MA, Tufail K, Malek AH, Balasubramanian M, Araya V. A new approach for treatment of hepatitis $C$ in hepatitis $C$-autoimmune hepatitis overlap syndrome. Gastroenterol Hepatol (N Y) 2010;6:233-236.

[119] CDC. Blood Safety. 2013

[120] Wilkins T, Akhtar M, Gititu E, Jalluri C, Ramirez J. Diagnosis and management of hepatitis C. Am Fam Physician 2015;91:835-842.

[121] Chung RT, Andersen J, Volberding P, Robbins GK, Liu T, Sherman KE, et al. Peginterferon Alfa-2a plus ribavirin versus interferon alfa-2a plus ribavirin for chronic hepatitis C in HIV-coinfected persons. N Engl J Med 2004;351: 451-459. doi: 10.1056/NEJMoa032653.

[122] Mehta SH, Lucas GM, Mirel LB, Torbenson M, Higgins Y, Moore RD, et al. Limited effectiveness of antiviral treatment for hepatitis $C$ in an urban HIV clinic. AIDS 2006;20:2361-2369. doi: 10.1097/QAD.0b013e32801086da.

[123] Simmons B, Saleem J, Hill A, Riley RD, Cooke GS. Risk of late relapse or reinfection with hepatitis $C$ virus after achieving a sustained virological response: a systematic review and meta-analysis. Clin Infect Dis 2016; 62:683-694. doi: 10.1093/cid/civ948.

[124] Chen MH, Chen MH, Tsai CY, Chou CT, Lin HY, Huang DF, et al. Incidence and antiviral response of hepatitis $C$ virus reactivation in lupus patients undergoing immunosuppressive therapy. Lupus 2015;24:1029-1036. doi: 10.1177/0961203315571465.

[125] Belda O, Targett-Adams P. Small molecule inhibitors of the hepatitis C virusencoded NS5A protein. Virus Res 2012;170:1-14. doi: 10.1016/j.virusres. 2012.09.007.

[126] Zaidan M, Mariotte E, Galicier L, Arnulf B, Meignin V, Vérine J, et al. Vasculitic emergencies in the intensive care unit: A special focus on cryoglobulinemic vasculitis. Ann Intensive Care 2012;2:31. doi: 10.1186/ 2110-5820-2-31.

[127] Rodrigo D, Perera R, de Silva J. Classic polyarteritis nodosa associated with hepatitis C virus infection: a case report. J Med Case Rep 2012;6:305. doi: 10.1186/1752-1947-6-305.

[128] Colucci G, Manno C, Grandaliano G, Schena FP. Cryoglobulinemic membranoproliferative glomerulonephritis: beyond conventional therapy. Clin Nephrol 2011;75:374-379. doi: 10.5414/CNP75374.

[129] Butterly S], Pillans $P$, Horn B, Miles R, Sturtevant J. Off-label use of rituximab in a tertiary Queensland hospital. Intern Med J 2010;40:443-452. doi: $10.1111 / \mathrm{j} .1445-5994.2009 .01988 . x$

[130] Koziolek MJ, Scheel A, Bramlage C, Groene HJ, Mueller GA, Strutz F. Effective treatment of hepatitis $\mathrm{C}$-associated immune-complex nephritis with cryoprecipitate apheresis and antiviral therapy. Clin Nephrol 2007;67: 245-249. doi: 10.5414/CNP67245.

[131] Saadoun D, Resche-Rigon M, Thibault V, Piette JC, Cacoub P. Antiviral therapy for hepatitis $C$ virus-associated mixed cryoglobulinemia vasculitis: a long-term followup study. Arthritis Rheum 2006;54:3696-3706. doi: 10. 1002/art.22168.

[132] Saadoun D, Aaron L, Resche-Rigon M, Pialoux G, Piette JC, Cacoub P. Cryoglobulinaemia vasculitis in patients coinfected with HIV and hepatitis $C$ virus. AIDS 2006;20:871-877. doi: 10.1097/01.aids.0000218551.62210.b5.

[133] Neri S, Pulvirenti D, Mauceri B, Ignaccolo L, Azzolina R. A case of progression from type II cryoglobulinaemia to Waldenstrom's macroglobulinaemia in a patient with chronic hepatitis C. Clin Exp Med 2005;5:40-42. doi: 10. 1007/s10238-005-0062-7.

[134] Méndez P, Saeian K, Reddy KR, Younossi ZM, Kerdel F, Badalamenti S, et al. Hepatitis C, cryoglobulinemia, and cutaneous vasculitis associated with unusual and serious manifestations. Am J Gastroenterol 2001;96:24892493. doi: 10.1016/S0002-9270(01)02622-3.

[135] Cacoub P, Maisonobe T, Thibault V, Gatel A, Servan J, Musset L, et al. Systemic vasculitis in patients with hepatitis C. J Rheumatol 2001;28: 109-118.

[136] Kiyomoto H, Hitomi H, Hosotani Y, Hashimoto M, Uchida K, Kurokouchi K, et $a l$. The effect of combination therapy with interferon and cryofiltration on mesangial proliferative glomerulonephritis originating from mixed cryoglobulinemia in chronic hepatitis C virus infection. Ther Apher 1999;3:329333. doi: 10.1046/j.1526-0968.1999.00196.x.

[137] David WS, Peine C, Schlesinger P, Smith SA. Nonsystemic vasculitic mononeuropathy multiplex, cryoglobulinemia, and hepatitis C. Muscle Nerve 1996;19:1596-1602. doi: 10.1002/(SICI)1097-4598(199612)19:12 $<1596$ : :AID-MUS9>3.3.CO;2-6.

[138] Gentile I, De Stefano A, Di Flumeri G, Buonomo AR, Carlomagno C, Morisco $\mathrm{F}$, et al. Concomitant interferon-alpha and chemotherapy in hepatitis $\mathrm{C}$ and colorectal cancer: a case report. In Vivo 2013;27:527-529.

[139] Ayyub M, El-Moursy SA, Al-Abbas F. Outcome of combination antiviral therapy in chronic hepatitis $C$ virus infection during therapy of acute lymphoblastic leukemia. Saudi J Gastroenterol 2011;17:283-286. doi: 10. 4103/1319-3767.82586.

[140] Papaevangelou V, Varsami M, Papadakis V, Zellos A, Parcharidou A, Papargyri $\mathrm{S}$, et al. Hepatitis $\mathrm{C}$ treatment concomitant to chemotherapy as "salvage" therapy in children with hematologic malignancies. Pediatr Infect Dis J 2010;29:277-280. doi: 10.1097/INF.0b013e3181c2115a.

[141] Waldron P. Interferon treatment of chronic active hepatitis $C$ during therapy of acute lymphoblastic leukemia. Am J Hematol 1999;61:130-134. doi: 10. 1002/(SICI)1096-8652(199906)61:2<130: :AID-AJH10>3.0.CO;2-M.

[142] Pardo-Yules B, Gallego-Durán R, Eslam M, García-Collado C, Grande L, Paradas $C$, et al. Thalidomide with peginterferon alfa-2b and ribavirin in the treatment of non-responders genotype 1 chronic hepatitis $C$ patients: proof of concept. Rev Esp Enferm Dig 2011;103:619-625. doi: 10. 4321/S1130-01082011001200003. 